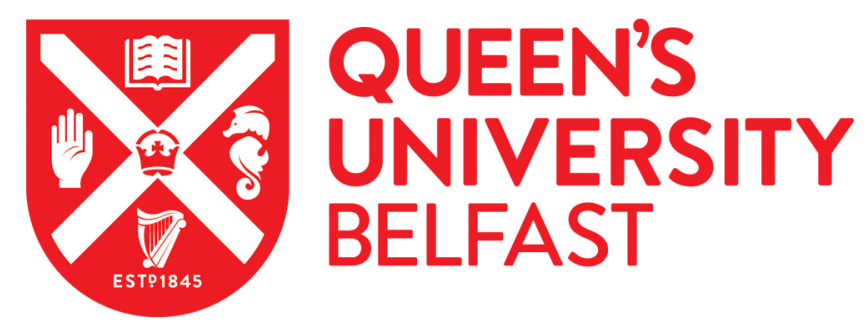

\title{
Evaluation of Mass Sensitive Micro-Array biosensors for their feasibility in multiplex detection of low molecular weight toxins using mycotoxins as model compounds
}

Nolan, P., Auer, S., Spehar, A., Oplatowska-Stachowiak, M., \& Campbell, K. (2021). Evaluation of Mass

Sensitive Micro-Array biosensors for their feasibility in multiplex detection of low molecular weight toxins using mycotoxins as model compounds. Talanta, 222, [121521]. https://doi.org/10.1016/j.talanta.2020.121521

Published in:

Talanta

Document Version:

Peer reviewed version

Queen's University Belfast - Research Portal:

Link to publication record in Queen's University Belfast Research Portal

Publisher rights
@ 2020 Elsevier B.V.
This manuscript is distributed under a Creative Commons Attribution-NonCommercial-NoDerivs
License.(https://creativecommons.org/licenses/by-nc-nd/4.0/), which permits distribution and reproduction for non-commercial purposes,
provided the author and source are cited.

General rights

Copyright for the publications made accessible via the Queen's University Belfast Research Portal is retained by the author(s) and / or other copyright owners and it is a condition of accessing these publications that users recognise and abide by the legal requirements associated with these rights.

\section{Take down policy}

The Research Portal is Queen's institutional repository that provides access to Queen's research output. Every effort has been made to ensure that content in the Research Portal does not infringe any person's rights, or applicable UK laws. If you discover content in the Research Portal that you believe breaches copyright or violates any law, please contact openaccess@qub.ac.uk. 


\title{
Evaluation of Mass Sensitive Micro-Array Biosensors for their feasibility in multiplex detection of low molecular weight toxins using mycotoxins as model compounds
}

\author{
P. Nolan ${ }^{1}$, S. Auer ${ }^{2}$, A. Spehar ${ }^{2}$, M. Oplatowska-Stachowiak ${ }^{1+}$ and K. Campbell ${ }^{1 *}$ \\ 1. Institute for Global Food Security, School of Biological Sciences, Queen's University Belfast, 19 \\ Chlorine Gardens, Belfast, UK BT9 5DL. \\ 2. BioMensio Limited, Hermiankatu 6-8H, 33720 Tampere, Finland.
}

* Corresponding author:

Prof. Katrina Campbell

Institute for Global Food Security

School of Biological Sciences

Queen's University, Belfast

19 Chlorine Gardens

UK BT9 5DL

Tel: +44 (0) 2890976535

E-mail: katrina.campbell@qub.ac.uk

+ Current address: R-Biopharm Nederland B.V., Beijerinckweg 18, 6827 BN Arnhem, The Netherlands

\begin{abstract}
Mycotoxins produced by Fusarium species including trichothecenes, zearalenone and fumonisins, can co-contaminate food and feed throughout the supply chain, including cereal grains and animal feeds. There is an increasing demand to enhance global food security by improving the monitoring of mycotoxins throughout our food supply chain. For time and cost-efficient analysis, rapid tests capable of detecting multiple toxins from a single sample are ideal. Considering these current trends in mycotoxin testing, this project examined the feasibility of using both a portable and non-portable mass-based biosensor for multiplex mycotoxin detection. The biosensor was a mass sensitive microarray (MSMA) which consisted of $4 \times 16$ miniaturized mass sensitive transducer pixels based on solidly mounted resonator (SMR) technology. Functionalisation of individual pixels on the sensor surface using nano-spotting technology for the simultaneous and semi-quantitative detection of three regulated mycotoxins: T2-toxin (T2) zearalenone (ZEN), and fumonisin B1 (FumB1) was examined. With the integration of portable and non-portable microfluidic devices for antibody and standard sample injections, competitive inhibition assays were developed followed by singleplex and multiplex calibration curves. The characteristics and performance of the MSMA were evaluated including sensitivity which was determined as the concentration causing $50 \%$ inhibition. Sensitivity of singleplex assays using the portable microfluidic device (PMD) were $1.3 \mathrm{ng} / \mathrm{ml}, 2.0 \mathrm{ng} / \mathrm{ml}$ and $6.8 \mathrm{ng} / \mathrm{ml}$ for T2, FumB1 and ZEN, respectively. Sensitivity of the multiplex assay again using the PMD was $6.1 \mathrm{ng} / \mathrm{ml}$, $3.6 \mathrm{ng} / \mathrm{ml}$ and $2.4 \mathrm{ng} / \mathrm{ml}$ for T2, FumB1 and ZEN, respectively. The PMD was an easy to use and highly sensitive screening tool which has been demonstrated for the multiplex detection of three regulated mycotoxins. Analysis was in real time and results were fully digital. Since detection of analytes was by mass it was both a label-free and cost-efficient method of analysis for mycotoxins.
\end{abstract}




\section{Graphical Abstract}

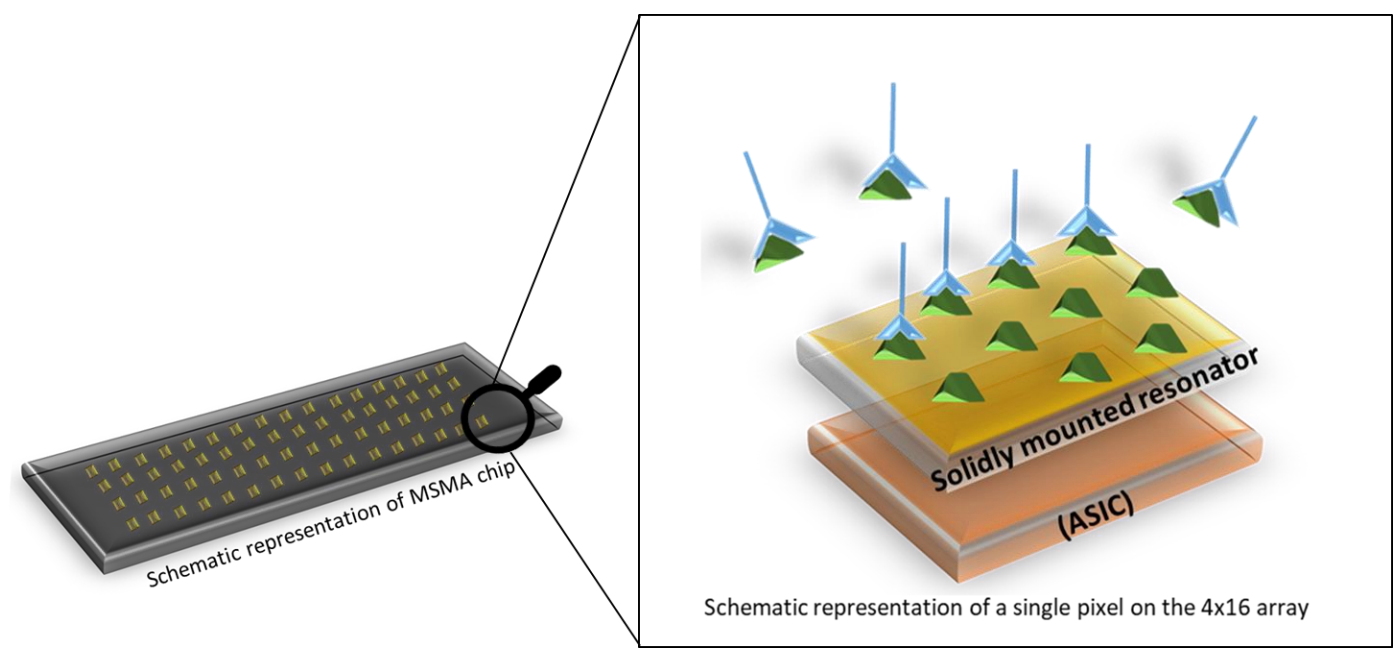

Keywords: mycotoxin; immunoassay; mass sensitive microarray biosensor; on-site detection; rapid detection method; multiplex detection 


\section{Introduction}

Mycotoxins are secondary metabolites produced by various fungi, the genera of which include Aspergillus, Penicillium and Fusarium [1,2]. Fumonisins (Fum), Zearalenone (ZEN) and T2/HT2 toxins, are amongst the most agriculturally significant mycotoxins in terms of being a health threat to humans and animals [3]. Therefore, maximum levels (MLs) at which these toxins can be present in food and feed, the sampling criteria and methods of analysis for their official control and performance criteria for screening methods have been set in European Regulations (EC) No 1881/2006, 401/2006 and $519 / 2014$ respectively $[4,5,6]$. The MLs for Fum (sum of B1 and B2) range from $200 \mu \mathrm{g} / \mathrm{kg}$ in baby foods to $2000 \mu \mathrm{g} / \mathrm{kg}$ in unprocessed maize, for ZEN the MLs range from $20 \mu \mathrm{g} / \mathrm{kg}$ in baby foods to $200 \mu \mathrm{g} / \mathrm{kg}$ in unprocessed maize and for T2/HT2 recommendations for MLs are still to be implemented. Though according to Commission Recommendation 2013/165/EU [7], the indicative levels range from 15ug/kg in baby foods to $1000 \mathrm{ug} / \mathrm{kg}$ in unprocessed cereals. To ensure food safety, numerous testing methods exist to prevent food and feed contaminated with high levels of mycotoxins reaching the consumer market. Liquid chromatography tandem mass spectrometry (LC-MS/MS) is currently extensively used as a confirmatory reference method, allowing the simultaneous determination of multiple mycotoxins [8]. This method however is limited to large commercial companies, reference and academic laboratories with skilled technicians and expensive laboratory equipment [9]. More user-friendly and inexpensive methods also exist including Enzyme Linked Immuno-Sorbent Assays (ELISAs) and Lateral Flow Immunoassays (LFIA) [10,11, 12] with progression in mycotoxin immunoassay testing reported using digital biosensor technology such as Surface Plasmon Resonance (SPR) and Quartz Crystal Microbalance (QCM).

Whilst biosensors based on film bulk acoustic resonators (FBAR) have not yet been used in mycotoxin analysis, the literature highlights its potential as a sensitive technique that could be exploited for the detection of mycotoxins. An FBAR transducer is based on a similar principle to QCM, however the piezoelectric material used in FBAR transducers is generally a thin film $(0.5-3 \mu \mathrm{m}$ thick) of aluminium nitride (AIN) or zinc oxide $(\mathrm{ZnO})[13,14]$ instead of bulk crystals. With these thin piezoelectric films, FBAR biosensors can ultimately provide better mass sensitivities than QCM as the FBAR transducer operates at higher frequencies. In biosensor development, FBARs must be isolated from the substrate to be functional, otherwise the acoustic waves generated by the piezoelectric film will radiate into the substrate, leading to no resonance. The structure of the FBAR is therefore crucial and can differ between devices. One commonly used structure is a solidly mounted resonator (SMR) which involves acoustically separating the resonator from the substrate by a stack of several materials including (SiO2) or Bragg mirrors (an acoustic mirror) (SiO2 and W) [15]. There can also be free standing FBARs with an air-cavity present. Due to the small size of the FBAR/SMR transducers, many of them can be integrated within a small area which gives an added advantage of high throughput and cost-effective analysis, with the possibility of developing a hand-held portable device [16].

In this study the feasibility of a novel multiplex immunoassay for mycotoxin analysis was determined using immunoreagents developed at Queens University Belfast (QUB) and a Mass Sensitive MicroArray (MSMA) [17] biosensor developed at BioMensio Ltd in Finland. The MSMA biosensor consists of $4 \times 16$ miniaturized mass sensitive transducer pixels based on SMR technology in combination with an application specific integrated circuit (ASIC) (Figure 1 (c)). This technology works under the same principles as QCM (Figure 1 (b)). The pixels, which make up the sensor surface, can be functionalized to detect a specific target or multiple targets. 


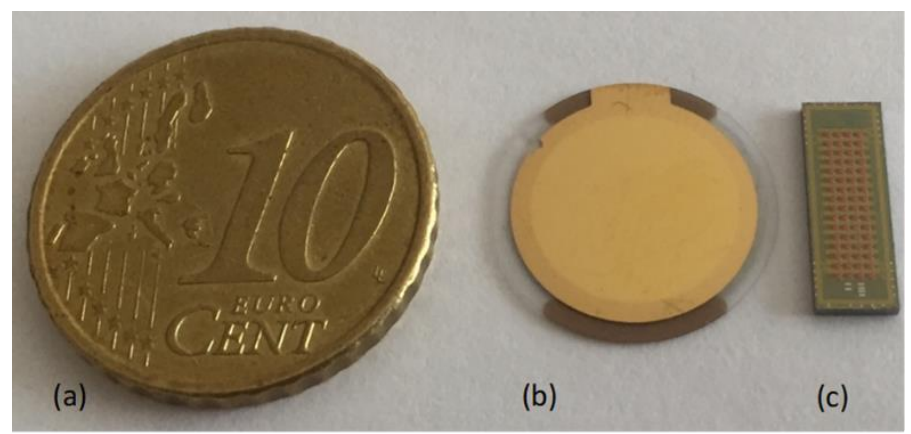

Figure 1. MSMA size (c) compared to a 10 cent coin (a) and QCM (b).

\section{Methods}

\subsection{Chemicals and Reagents}

Monoclonal Antibodies: T-2/HT-2 toxin monoclonal antibody was produced in another study [18]. Toxins (T2, FumB1 and ZEN) were purchased for protein conjugate and biosensor chip production (Sigma-Aldrich, Gillingham, UK). Toxin standards: T2, FumB1, FumB2, and FumB3 and ZEN were purchased from Romer labs (Getzersdorf, Austria). Zearalanone, $\alpha$-Zearalenol, $\beta$-Zearalenol, $\alpha-$ Zearalanol, $\beta$-Zearalanol were purchased from BioAustralis Fine Chemicals, Austrailia. Toxin standards were made up to $1 \mathrm{mg} / \mathrm{ml}$ stock solutions in acetonitrile (except FumB1 which was made up in 1:1 acetonitrile: water). HBS-EP buffer (0.01 M HEPES pH 7.4, $0.15 \mathrm{M} \mathrm{NaCl}, 3 \mathrm{mM}$ EDTA, $0.005 \% \mathrm{v} / \mathrm{v}$ Surfactant P20), amine coupling kit with 1-ethyl-3-(3-dimethylaminopropyl) carbodiimide hydrochloride (EDC) and N-hydroxysuccinimide (NHS) were purchased from GE Healthcare Life Sciences. PBS ( $100 \mathrm{mM}$ sodium phosphate, $50 \mathrm{mM}$ sodium chloride, $100 \mu \mathrm{g} / \mathrm{ml} \mathrm{BSA}$, $0.005 \%$ Tween-20, $\mathrm{pH}$ 8.0), carboxymethoxylamine (CMO), sodium dodecyl sulfate (SDS), TWEEN 20 , sodium chloride, acetone, isopropanol, ammonium hydroxide, hydrogen peroxide and sulfuric acid were purchased from Sigma-Aldrich, Gillingham, UK.

\section{$\underline{2.2 \text { Instrumentation }}$}

Safire $^{2}$ Tecan ELISA plate reader (Tecan Diagnostics, Switzerland), Biacore $Q$ and research grade CM5 sensor chips (GE Healthcare Life Sciences. Uppsala, Sweden) and MSMA technology, non-portable and portable microfluidic devices (BioMensio Ltd, Finland) were utilised in this study. 


\subsection{Toxin protein conjugates}

An immunogen (FumB1-BSA) for the production of anti-FB1 mAbs, a coating antigen (FumB1-KLH) for screening of mAbs by antigen-coated ELISA and MSMA technology and FumB1-OVA, were produced in accordance with the method described in Sheng et al [19] using standard carbodiimide chemistry (figure 2).

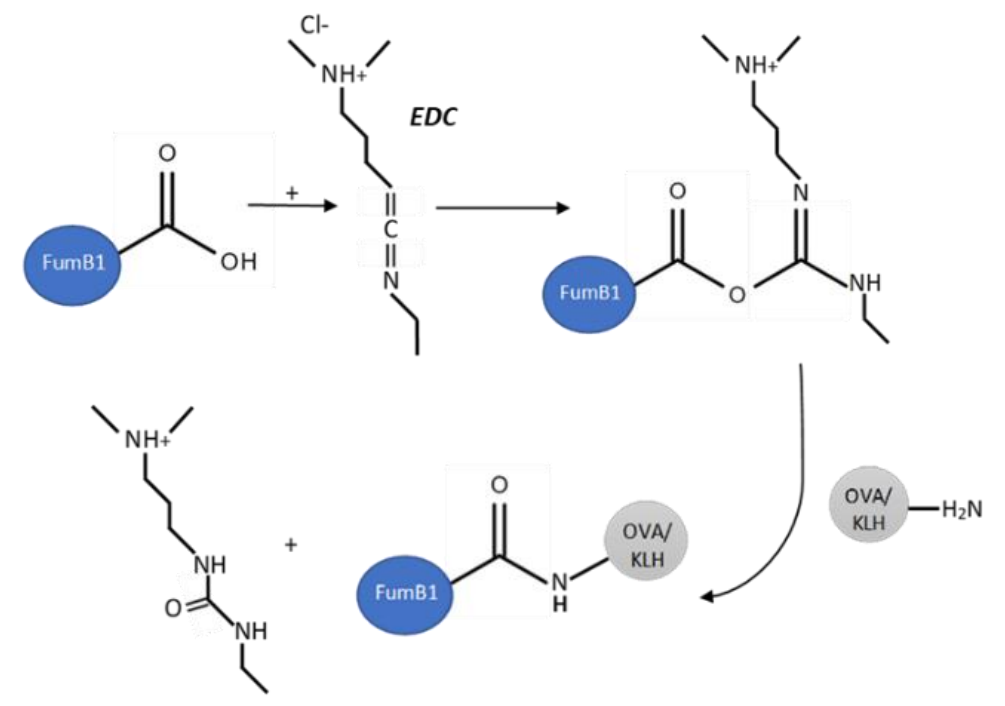

Figure 2. Schematic representation of FumB1 conjugation to OVA or KLH protein via carbodiimide chemistry.

An immunogen (ZEN-BSA) for the production of anti-ZEN mAbs and a coating antigen (ZEN-KLH) for initial hybridoma screening were produced in accordance with the method described in Cha et al [20]. Further conjugates for coating antigens ZEN-KLH and ZEN-OVA were produced using a carboxymethoxylamine linker via carbodiimide chemistry similar to that used for aflatoxin (figure 3 ) [21]. T2-Transferrin was produced as described previously for HT2 biosensor chip surfaces [22].

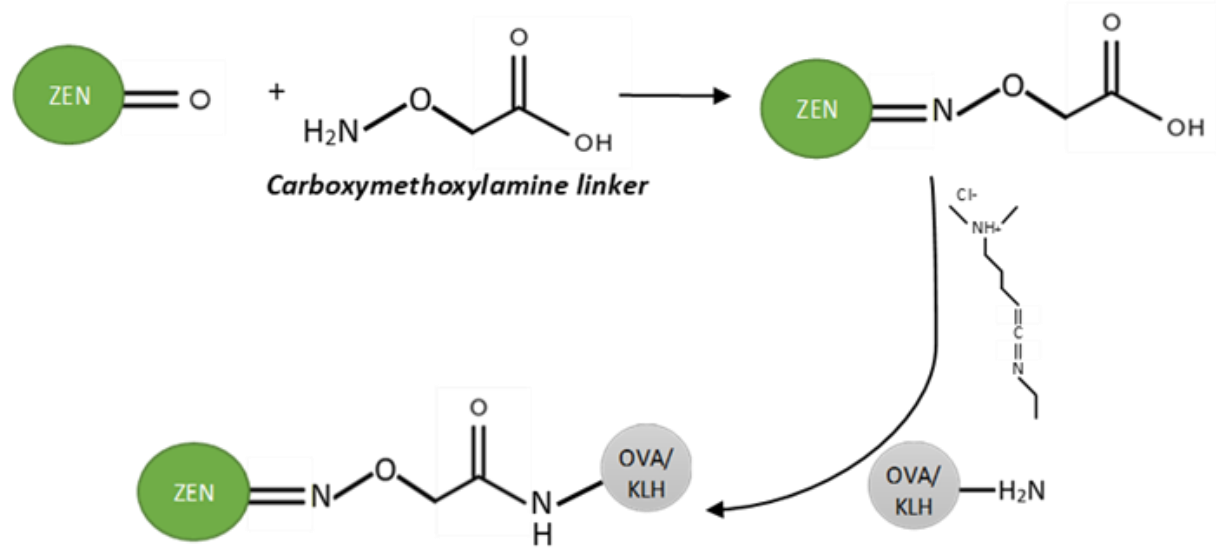

Figure 3: Schematic representation of ZEN conjugation to OVA and KLH protein carboxymethoxylamine linker via carbodiimide chemistry

\subsection{Monoclonal antibodies (mAbs)}

Anti-FB ${ }_{1}$ and anti-ZEN mAbs were produced by immunising mice with $15 \mu \mathrm{g}$ of FumB1-BSA or ZEN-BSA per injection in accordance with the procedure described previously [23] as conducted under project licence PPL2756 [24]. Antibody titer and sensitivity were monitored by testing blood samples collected 
10 days after each injection. The method used for testing was an antigen-coated ELISA with FumB1BSA or ZEN-BSA as coating antigens. The splenocytes from animals showing the best response in titre and sensitivity were fused with SP2 myeloma cells using an adapted method of Kohler and Milstein [24] as described previously for aflatoxin monoclonal antibody production [23]. mAbs from selected cell lines were produced in flasks, purified and characterised in an antigen-coated ELISA similar to that described previously [23]. The protein concentration and isotyping of each antibody was determined at A280 nm and using a mouse monoclonal antibody isotyping kit (Roche Diagnostics), respectively. The antibody was stored frozen at $-20 \mathrm{C}$ until required for use. The $\mathrm{IC}_{50}$ and cross-reactivity profiles of the selected antibody for each target, $\mathrm{FB}_{1}$ and $\mathrm{ZEN}$, utilised in this study were determined and for the variety of congeners commercially available, respectively.

\subsection{Characterising reagents by ELISA}

\subsubsection{Assay protocol for indirect competitive ELISA}

Microtiter plates were coated with toxin-conjugate $(5 \mu \mathrm{g} / \mathrm{ml}$ or $2.5 \mu \mathrm{g} / \mathrm{ml}, 100 \mu \mathrm{l}$ per well) diluted in 50 $\mathrm{mM}$ sodium carbonate/bicarbonate buffer $\mathrm{pH} 9.6$ and left overnight at $4^{\circ} \mathrm{C}$ in the dark. The plates were blocked using milk powder (Marvel, $2 \%$ ) and incubated for 1 hour at $37^{\circ} \mathrm{C} .50 \mu \mathrm{l}$ of toxin-specific antibody dilutions and $50 \mu \mathrm{l}$ of standards (in the range of $0-200 \mathrm{ng} / \mathrm{ml}$ for FumB1 and ZEN and 0$20,000 \mathrm{ng} / \mathrm{ml}$ for T2) prepared in pH7.2 phosphate buffer were added to the appropriate wells and incubated for 3 hours $\left(37^{\circ} \mathrm{C}\right)$. The antibody-standard mixtures were then discarded and the plate washed four times with wash buffer $(0.15 \mathrm{M} \mathrm{NaCl}, 10 \%$ TWEEN 20). After tapping dry, $100 \mu \mathrm{l}$ of goat anti-mouse peroxidase labelled antibody (1/2000 diluted in phosphate buffer) was added to each well, and incubated for 55 minutes at $37^{\circ} \mathrm{C}$. The $2^{\circ}$ antibody was discarded, the plate was washed 8 times with wash buffer and tapped dry before the addition of $100 \mu \mathrm{l}$ of TMB-E. The plate was left for 5 minutes in the dark to allow colour development then stopped with $25 \mu$ l of a solution of $2.5 \mathrm{M}$ sulfuric acid. Absorbance was read at $450 \mathrm{~nm}$ with Magellan software (Version 5.3). Initially, checkerboards of antibody versus conjugate concentrations were assessed with one toxin standard at a set concentration to determine the optimal reagent concentrations for use in the ELISA. Thereafter, using the optimum antibody and conjugate concentrations, varying concentrations of standards were assessed to generate calibration curves.

\subsubsection{Data interpretation}

Calibration curves were generated by plotting the average $\mathrm{OD}$ from replicates vs the log concentration of standard to obtain $\mathrm{IC}_{50}, \mathrm{IC}_{20}$ and $\mathrm{IC}_{80}$ values. The calibration curves were fitted with a regression curve using GraphPad Prism (Version 7.0, GraphPad Software Inc., USA).

\subsection{Characterising reagents via SPR}

\subsubsection{Toxin Immobilisation onto SPR chip surface}

The immobilization procedures were performed under static conditions on the bench. Between each stage the solutions were removed by tissue, taking care not to touch the centre of the sensing surface. Briefly, ZEN-CMO was prepared the day before chip conjugation by reacting ZEN toxin $(4.3 \mathrm{mg})$ with $\mathrm{CMO}(5.6 \mathrm{mg})$ in pyridine $(500 \mu \mathrm{l})$ overnight. $1 \mathrm{mg}$ of FumB1 was made up in $500 \mu \mathrm{L}$ water. The $\mathrm{CM} 5$ sensor chips were allowed to equilibrate to room temperature and primed using water. The surfaces were activated by pipetting onto them a 1:1 mixture of $0.4 \mathrm{M} \mathrm{EDC/0.1} \mathrm{M} \mathrm{NHS} \mathrm{for} 30 \mathrm{~min}$. An amine (2,2 -(ethylenedioxy)bis(ethylamine)) (0.1M made up in water) was applied for $1 \mathrm{~h}$ followed by deactivation of un-reacted sites using $1 \mathrm{M}$ ethanolamine, $\mathrm{pH} 8.5$ for $30 \mathrm{~min} .10 \mu \mathrm{L}$ of FumB1 and $9.4 \mu \mathrm{L}$ ZEN-CMO solution were mixed 1:1:2 with $0.4 \mathrm{M} \mathrm{EDC/0.1} \mathrm{M} \mathrm{NHS/phosphate} \mathrm{buffer} \mathrm{pH} 7.2$ and applied to the surfaces of the respective chips. The T2 chip was prepared as previously described for HT2 [22]. The chips were left overnight at room temperature. The following day the sensor chips were washed with deionized water $\left(\mathrm{dH}_{2} \mathrm{O}\right)$ and dried under a gentle stream of nitrogen. When not in use the sensor chips were placed in a storage package containing desiccant at $+4{ }^{\circ} \mathrm{C}$. 


\subsubsection{Assay Protocol}

The standards and samples were pre-mixed and immediately transferred to vials held within a rack. The flow rate was set at $25 \mu \mathrm{L} / \mathrm{min}$ and the contact time was 1 minute for each mixture and regeneration. Using the control software, the chips were first optimised for antibody regeneration solutions ( $100 \mathrm{mM} \mathrm{HCL}$ for ZEN and FumB1 chips and $250 \mathrm{mM} \mathrm{HCL} / 0.5 \%$ SDS for T2 chip). Prior to analysis each chip was then initially regenerated. This was followed by subsequent injections over the surface of the sensor chip of antibody-standard mixtures. Between each injection of antibody, the chip surface was regenerated and the needle and flow cell washed.

\subsubsection{Data interpretation}

Report points were recorded 10 seconds before and 30 seconds after each injection to determine the relative response for each. Calibration curves were generated by plotting the average response from replicates vs the log concentration of standard to obtain $I C_{50}, I C_{20}$ and $I C_{80}$ values. The calibration curves were fitted with a regression curve using GraphPad Prism (Version 7.0, GraphPad Software Inc., USA).

\subsection{Mass Sensitive Microarray (MSMA) technology}

\subsubsection{SMR's}

The piezoelectric material of the SMR's used in this study was zinc oxide $(\mathrm{ZnO})$ (500nm thick) which was sandwiched between two electrodes. A silicon dioxide ( $\mathrm{SiO}$ ) layer coats the top electrode which isolates it from the sample liquid. A thin gold layer on top of the SiO2 isolation layer served as the sensor surface for functionalisation of toxin-conjugates. These five components of the SMR are mounted on top of an acoustic mirror which in turn is mounted upon the substrate (figure 4). The fundamental resonance frequency of the SMR was approximately $800 \mathrm{MHz}$ which decreased when additional mass was added on top of the resonator. The resonance frequency could be determined in real time using in house developed Labview based measurement software. The resonators were arranged in an array of $4 \times 16$ squared electrodes that were $200 \mu \mathrm{m} \times 200 \mu \mathrm{m}$, comprising the MSMA.
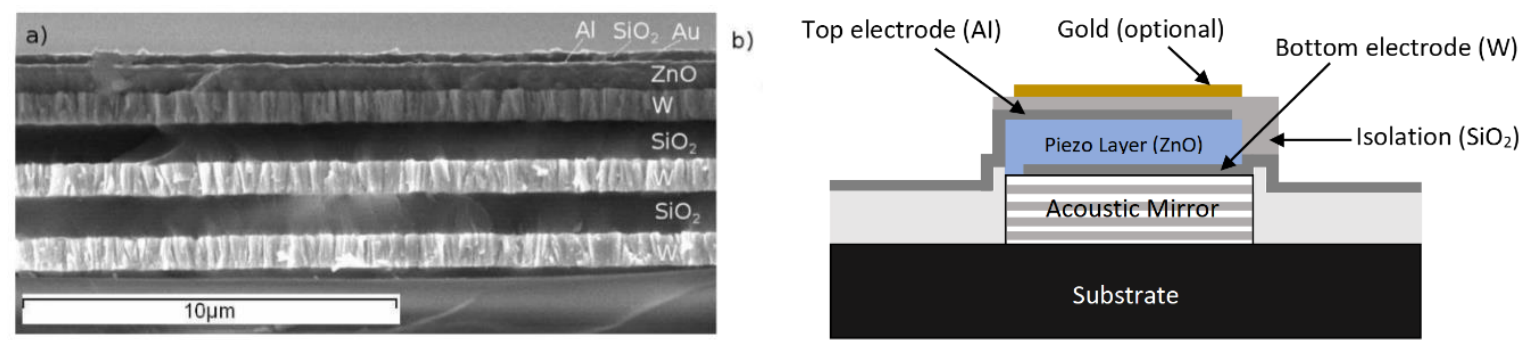

Figure 4 (a) SEM picture and (b) an illustration showing the SMR stack: The piezoelectric layer is sandwiched between a top (aluminium) and bottom (tungsten) electrode. The resonator is built on top of an acoustic mirror consisting of alternating layers of tungsten and SiO2. The resonator is isolated from the liquid environment with another layer of SiO2. An additional gold layer on top of the SMR is for functionalisation of analytes. Images from Nirschl 2010 [16].

\subsubsection{MSMA chip regeneration}

The sensor surface could be regenerated whereby toxin-conjugates were removed from the pixel's surface using a 1:1:5 mixture of ammonium hydroxide, hydrogen peroxide and $\mathrm{dH}_{2} \mathrm{O}$. The mixture was brought to boiling point using a hotplate. Three drops of the mixture were placed onto the sensor surface using a plastic pipettes for 20 seconds followed by rinsing off with $\mathrm{dH}_{2} \mathrm{O}$ and drying with 
nitrogen. For the chips used in this project, this regeneration protocol was used a maximum of three times per chip before they were unable to be reused.

\subsubsection{Signal acquisition}

Under each FBAR pixel there was a dedicated read-out circuit. Each pixel could be contacted and read out separately which allowed for multiplexed parallel measurements. The resonator set-up and readout methods are described in detail by Nirschl et al. $[17,25]$ The operational frequency point of each individual resonator was adjusted on the D/A-converter curve.

\subsubsection{Non-portable and portable MSMA devices}

MSMA sensors are fabricated by unique technology owned by Biomensio and are not commercially available, therefore Biomensio have developed two of their own measurement devices; a nonportable benchtop lab analyser for automated analysis, and a portable device for on-site measurement. The same sensor can be used in both devices. There are four main elements common to both devices: the buffer and sample vial rack, the peristaltic pump, the sensor docking station and the waste and collection vial rack. The docking station is where the MSMA chip is docked and it consists of a reader board that detects the signal generated from the SMR pixels. The reader board connects via a Micro-USB directly to a laptop where the Labview software displays the frequency signal in real time. What differs between the devices are the fluidic systems into which they are integrated.

\section{Non-portable device}

The Non-Portable Microfluidic Device (NPMD) was developed in collaboration with BioNavis Ltd (www.bionavis.com), utilising an altered version of the commercially available fluidic system developed by BioNavis for their SPR device. For the MSMA sensors, the fluidic system is modified to include a customised 4-channel flow cell. The fluidic system is still controlled by BioNavis software developed for their SPR devices. Using this software, the fluidic system firstly brings the 4-channel flow cell into contact with the surface of the docked chip. This contact is sealed and enclosed around the housing of the pixels. The channels of the flow cell divide the pixels into 4 rows. Each flow cell has an inlet connected to a tube that carries sample from the sample vial rack through that flow cell and over the pixels on the surface of the chip. Each flow cell also has an outlet connected to a tube that then carries the sample to the waste and collection vial rack. A single needle brings the reagent from the sample vial rack (which holds a microtiter plate) through either flow channel 1, 2, 3 or 4 (Figure $5(a$ and $c)$ ). These parameters are set prior to running the assay using the software.

\section{Portable device}

The Portable Microfluidic Device (PMD) is not automated and the microfluidic system in this device is simpler as it only has one channel (Figure $5(b$ and $d)$ ). Prior to setting up the system, the MSMA chip is attached to a one channel cartridge via the housing surrounding the pixels. The chip is then ready to be docked in the docking station. The cartridge allows the controlled flow of sample directly onto the pixels on the sensor's surface. The cartridge has an inlet and outlet, for Tube $A$ and Tube B, respectively. A needle connected to Tube A carries sample from the sample vial rack (which holds Eppendorf tubes) through the one channel cartridge and over the sensor surface via peristaltic pumping. After passing across the surface of the sensor, Tube B carries the sample to the waste and collection vial rack. 

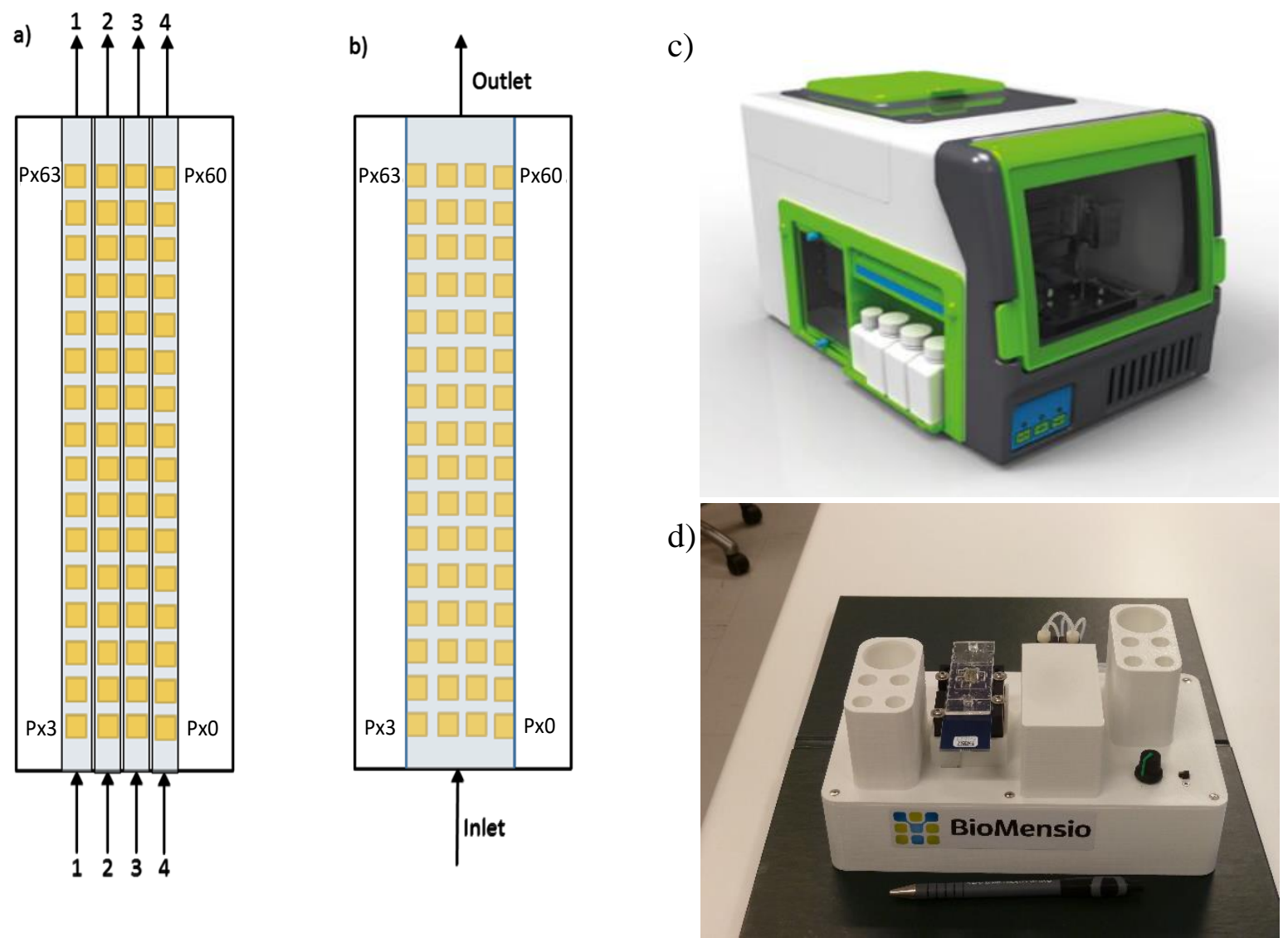

Figure 5. Schematic representation of sample distribution upon injection over the MSMA using the four channel NPMD chip a) and c) and the one channel PMD b) and d).

\subsubsection{Data analysis}

Using Microsoft ${ }^{\circ}$ Excel (2016) the frequency change $(\Delta f)$ was evaluated by plotting pixel frequency over time points on a graph (time points were recorded every 7 seconds). To determine the relative $\Delta f$ for each injection, report points were recorded by taking an average of the pixel's frequencies at 5 time points before and after $A b$ injection. The average $\Delta f$ of the number of pixels analysed during that injection was then calculated removing outliers (three standard deviations of the mean or one standard deviation of the mean if chips had been regenerated near the ir maximum threshold) and non-functioning pixels. For comparison between runs, results were normalised to $\mathrm{B} / \mathrm{B}_{0}(\%)$ so that the $\Delta \mathrm{f}$ generated by the $\mathrm{Ab}$ mixed with the respective toxin standard (B) was divided by the $\Delta f$ generated by $A b$ in the absence of standard $\left(B_{0}=100 \%\right) \times 100 . B_{0}$ is defined as maximum response generated upon binding of an $A b$ injection to which response of the injection containing the same concentration of $A b$ with the addition of toxin standard can be compared to obtain a percentage bound. Variation is defined as \%CV and indicated by error bars. The calibration curves were fitted with a regression curve using GraphPad Prism (Version 7.0, GraphPad Software Inc., USA) for determination of $\mathrm{IC}_{50}, \mathrm{IC}_{20}$ and $\mathrm{IC}_{80}$. 


\subsection{Initial testing on the Non-Portable MSMA Microfluidic Device}

\subsubsection{Toxin-protein conjugate Immobilisation onto the chip surface}

Mycotoxin-conjugates were diluted in PBS at $50 \mu \mathrm{g} / \mathrm{ml}$ and mixed with $100 \mu \mathrm{g} / \mathrm{ml}$ of N[Tris(hydroxymethyl)methyl]acrylamide (pTHMMAA) polymer for the first analysis. This concentration of pTHMMAA and mycotoxin-conjugate were chosen based on previous experiments carried out on MSMA technology with other analytes [25]. The surfaces of the chips were coated manually using a pipette with $12 \mu \mathrm{l}$ of either FumB1-KLH, T2-Transferrin or ZEN-KLH coating solutions. pTHMMAA acted as a blocking agent [26]. Prior to coating, the chips were cleaned by rinsing with acetone, isopropanol and $\mathrm{dH}_{2} \mathrm{O}$ then dried off with nitrogen. After coating the chip was left covered at room temperature for 30 minutes before being rinsed with water once more, dried off with nitrogen and stored until further use at $4^{\circ} \mathrm{C}$.

\subsubsection{Assay Protocol}

Prior to starting the assay, the device was cleaned by running $0.5 \%$ SDS through the entire microfluidic system, followed by priming with PBS (pH 8.0, 0.01M). Using the system software, the flow rate $(30 \mu \mathrm{l} / \mathrm{min})$ and the flow channels for each injection of a certain antibody-standard mixture $(400 \mu l)$ were selected. At the appropriate concentrations, antibody-standard mixtures were transferred to the wells of a microtiter plate. The device was automated and injections occurred subsequently thereafter. The response of the appropriate pixels was detected and measured in real time by the system software. All analyses were performed at a temperature of $25^{\circ} \mathrm{C}$.

\subsubsection{Assay Development}

A checkerboard titration was used to assess binding to the surface and the optimal antibody concentration required to generate a suitable response. Initially, two concentrations of antibody were tested on one chip, a high concentration of $5 \mu \mathrm{g} / \mathrm{ml}$ injected through flow channel 1 and a low concentration of $0.5 \mu \mathrm{g} / \mathrm{ml}$ injected through flow channel 3. Through flow channel 2 and 4 , $200 \mathrm{ng} / \mathrm{ml}$ of toxin standard was mixed with either the $5 \mu \mathrm{g} / \mathrm{ml} \mathrm{Ab}$ solution or $0.5 \mu \mathrm{g} / \mathrm{ml}$ Ab solution, respectively. For ZEN $m A B$ a further refinement of antibody concentration was required. The optimised concentrations were $5 \mu \mathrm{g} / \mathrm{ml}$ of $\mathrm{T} 2 \mathrm{mAB}$ and FUM $\mathrm{mAB}$ and $10 \mu \mathrm{g} / \mathrm{ml}$ of ZEN mAB (Fig. S1).

\subsection{Assay Optimisation on Portable MSMA technology}

\subsubsection{Toxin-protein conjugate Immobilisation onto the chip surface}

Using the nano-spotter software system, a target substrate for the MSMA chips was developed. The target (starting point) for the spotting needle was aligned to the first pixel on the chip within the housing. One chip was aligned and spotted at a time as not all pixels on different chip batches were at the same exact position within the housing. Various spotting volumes of the protein conjugate and polymer mixtures were tested to determine the best surface coverage of the spots on individual pixels. A spotting volume of $9000 \mathrm{pL}$ was suitable for full coverage of the surface. After spotting, the chip was left in the Scienion sciFLEXARRAYER for 30 minutes before being rinsed with $\mathrm{dH}_{2} \mathrm{O}$ once more, dried off with nitrogen and stored until further use at $4^{\circ} \mathrm{C}$.

\subsubsection{Assay Protocol}

Using the pump controller, the flow rate was set to $50 \mu \mathrm{l} / \mathrm{min}$. The system was firstly cleaned by running $0.5 \%$ SDS through the entire microfluidic system, followed by priming with PBS. The analysed $\mathrm{Ab}$-standard mixture was pre-incubated for $45 \mathrm{~min}$ at $37^{\circ} \mathrm{C}$ prior to analysis. A mixture $(500 \mu l)$ was then flowed onto the surface of the pixels through the one channel cartridge and the response of the pixels was detected and measured in real time by the system software. 


\subsubsection{Conjugate: Polymer ratio}

Different concentrations of conjugate $(25-150 \mu \mathrm{g} / \mathrm{ml})$ and polymer $(25-100 \mu \mathrm{g} / \mathrm{ml})$ mixtures were hand spotted onto the surface of the chip. Using the PMD, the optimised Ab dilution as determined through initial $\mathrm{Ab}$ chequerboard tests described in 2.8.3, was passed over the surface of the chip. The best suited conjugate: polymer ratio was based on the response of the $\mathrm{Ab}$ and the $\% \mathrm{CV}$ of all analysed pixels (Table 1).

\subsubsection{Singleplex curves}

The surfaces of the MSMA chips were coated using the Scienion sciFLEXARRAYER as described in 2.9.1, at the optimised conjugate: polymer ratio $(50 \mu \mathrm{g} / \mathrm{ml}: 100 \mu \mathrm{g} / \mathrm{ml}$ for T2 assay and $50 \mu \mathrm{g} / \mathrm{ml}: 50 \mu \mathrm{g} / \mathrm{ml}$ for FumB1 and ZEN assays). A maximum of six chips were spotted with one analyte for each of the three mycotoxin-conjugates used in this study. For all toxin assays, the standards ranged from $0 \mathrm{ng} / \mathrm{ml}$ to $100 \mathrm{ng} / \mathrm{ml}$. One Ab-standard mixture $(5 \mu \mathrm{g} / \mathrm{ml}$ of T2 $\mathrm{mAB}$ and FUM $\mathrm{mAB}$ and $10 \mu \mathrm{g} / \mathrm{ml}$ of ZEN mAB) was passed across the surface of one chip at a time using the one channel PMD. Runs were conducted in order from $0 \mathrm{ng} / \mathrm{ml}$ to $100 \mathrm{ng} / \mathrm{ml}$.

\subsubsection{Intra and inter -spotting precision}

The average $\Delta f$ upon injection of $A b$ from all functioning pixels was calculated and compared over the three different spotting days. Intra and inter spotting precision was determined from the coefficient of variation (\%CV). For intra-spotting precision: \%CV=Standard deviation of 64 pixels of one MSMA chip/Mean intensity of pixels of one MSMA chip $\times 100$. For inter-spotting precision: $\% C V=S t a n d a r d$ deviation of pixels from three MSMA chips/Mean intensity of pixels from three MSMA chips $\times 100$.

\subsubsection{Assay Interference}

4 chips per toxin-conjugate were coated (conjugate: polymer ratio of $50 \mu \mathrm{g} / \mathrm{ml}: 100 \mu \mathrm{g} / \mathrm{ml}$ for T2, $50 \mu \mathrm{g} / \mathrm{ml}: 50 \mu \mathrm{g} / \mathrm{ml}$ for FumB1 and ZEN) using the Scienion sciFLEXARRAYER as described in 2.9.1 in a singleplex system. On one chip the Ab specific to that toxin-conjugate was flowed over the pixels surface. Another chip was subject to Ab mixed with $200 \mathrm{ng} / \mathrm{ml}$ of toxin standard, specific to that $A b$, where inhibition would be expected. The other two chips were subject to Ab that was mixed with unspecific standard. Ab's were diluted to the optimised concentrations of $5 \mu \mathrm{g} / \mathrm{ml}$ for T2 mAB and FUM $\mathrm{mAB}$ and $10 \mu \mathrm{g} / \mathrm{ml}$ for ZEN mAB. The $\Delta \mathrm{f}$ obtained with non-specific standard was compared to the $\Delta \mathrm{f}$ obtained with specific standard.

\subsubsection{Multiplex curves}

The surfaces of the MSMA chips were coated using the Scienion sciFLEXARRAYER as described in 2.9.1, at the optimised conjugate: polymer ratio $(50 \mu \mathrm{g} / \mathrm{ml}: 100 \mu \mathrm{g} / \mathrm{ml}$ for T2 assay and $50 \mu \mathrm{g} / \mathrm{ml}: 50 \mu \mathrm{g} / \mathrm{ml}$ for FumB1 and ZEN assays). As there were three analytes under study, the surface of the chip was split into three different spotting sections. The pixels were divided into three sections. Pixels 0-19 were spotted with T2 coating solution, pixels 20-39 were spotted with ZEN coating solution and pixels 4063 were spotted with FumB1 coating solution. A maximum of 6 chips were spotted at a time per run. A range of standards were chosen based off the results obtained from singleplex analysis conducted with the Scienion sciFLEXARRAYER, 0-10ng/ml for T2 and 0-50ng/ml for ZEN and FumB1. 


\section{Results}

\subsection{Antibody production}

A monoclonal antibody for each target from the antibody production was selected for the evaluation of the prototype biosensor technology. The isotype for the ZEN (3E7) and $\mathrm{FB}_{1}$ (14E8) monoclonal antibodies produced were $\operatorname{IgG} 2 \mathrm{~b}, \mathrm{k}$ and $\operatorname{IgG} 1, \mathrm{k}$ respectively. The cross-reactivity of the monoclonal antibody (3E7) to zearalenone (ZEN), zearalanone, $\alpha$-Zearalenol, $\beta$-Zearalenol, $\alpha$-Zearalanol, $\beta$ Zearalanol was $100 \%, 12 \%, 15 \%, 8 \%, 9 \%$ and $11 \%$ respectively. The cross-reactivity of the monoclonal antibody to fumonisin B1, B2 and B3 was $100 \%, 123 \%$ and $11 \%$. For T2 MAB the cross-reactivity had been previously determined with HT-2 cross-reactivity reported at $5.4 \%$ and no cross-reactivity with deoxynivalenol, nivalenol, zearalenone, and neosolaniol [18].

\subsection{ELISA characterisation}

The optimised conditions by ELISA were a coating antigen concentration of $5 \mu \mathrm{g} / \mathrm{ml}$ for each toxin assay, with antibody concentrations of $0.13,0.03$ and $0.06 \mu \mathrm{g} / \mathrm{ml}$ for T2, FumB1 and ZEN assays, respectively. The secondary Ab dilution was applied at a dilution of 1 in 2000. The calibration curves showed good linearity (Fig S2) and sensitivity as indicated by the $\mathrm{IC}_{50}$ values were $0.20 \mu \mathrm{g} / \mathrm{ml}$, $6.05 \mathrm{ng} / \mathrm{ml}$ and $8.54 \mathrm{ng} / \mathrm{ml}$ for T2, FumB1 and ZEN, respectively (Table 2).

\subsection{SPR characterisation}

The optimised conditions by Biacore SPR were a coating concentration of $100 \mu \mathrm{g} / \mathrm{ml}$ with antibody dilutions of 4,20 and $8 \mu \mathrm{g} / \mathrm{ml}$ for T2, FumB1 and ZEN assays, respectively. Sensitivity as indicated by the $\mathrm{IC}_{50}$ values, calculated from the calibration curves (Fig S3), were $2.61 \mathrm{ng} / \mathrm{ml}, 15.06 \mathrm{ng} / \mathrm{ml}$ and $40.17 \mathrm{ng} / \mathrm{ml}$ for T2, FumB1 and ZEN, respectively (Table 2).

\subsection{Checkerboard titration on Non-Portable MSMA technology}

The optimised $A b$ concentrations moving forward with assay development were $5 \mu \mathrm{g} / \mathrm{ml}$ for T2 coated chips and FumB1 coated chips and $10 \mu \mathrm{g} / \mathrm{ml}$ for ZEN coated chips (Fig S1).

\subsection{Conjugate: Polymer ratio on Portable MSMA technology}

Table 1 indicates the parameters of the T2, FumB1 and ZEN assays evaluated with different concentration ratios of conjugate: polymer using the optimised $A b$ concentrations $(5 \mu \mathrm{g} / \mathrm{ml}$ of $\mathrm{T} 2 \mathrm{mAB}$ and FUM $\mathrm{mAB}$ and $10 \mu \mathrm{g} / \mathrm{ml}$ of ZEN mAB). The data in bold shows the best results generated for that particular toxin, based on a \%CV below or close to 15 . 
Table 1. Parameters of T2, FUMB1 and ZEN assays evaluated with different concentration ratios of conjugate: polymer and optimised Ab dilutions.

\begin{tabular}{|c|c|c|c|c|c|c|}
\hline Conjugate & $\begin{array}{c}A b \\
\text { Dilution }(\mu \mathrm{g} / \mathrm{ml})\end{array}$ & $\begin{array}{c}\text { Conjugate:Polymer } \\
(\mu \mathrm{g} / \mathrm{ml})\end{array}$ & Mean & $S D$ & Median & $\% C V$ \\
\hline T2-Transferrin & 5 & $50: 100$ & 533.5 & 65.8 & 515.0 & 12.3 \\
\hline \multirow{3}{*}{ ZEN-KLH } & \multirow{3}{*}{10} & $50: 100$ & 262.2 & 60.1 & 287.3 & 22.9 \\
\hline & & $50: 50$ & 306.9 & 42.4 & 305.6 & 13.8 \\
\hline & & $25: 50$ & 162.5 & 86.3 & 146.1 & 53.1 \\
\hline \multirow[b]{2}{*}{ FumB1-KLH } & \multirow[b]{2}{*}{5} & $50: 100$ & 413.6 & 80.4 & 446.7 & 19.4 \\
\hline & & $50: 50$ & 240.8 & 24.4 & 243.4 & 10.1 \\
\hline \multirow{5}{*}{ FumB1-OVA } & \multirow{5}{*}{5} & $100: 50$ & 212.2 & 35.1 & 226.1 & 16.5 \\
\hline & & $50: 50$ & 168.4 & 41.2 & 177.7 & 24.5 \\
\hline & & $100: 100$ & 117.3 & 20.0 & 117.7 & 17.1 \\
\hline & & $75: 50$ & 217.8 & 33.7 & 207.8 & 15.5 \\
\hline & & $150: 25$ & 271.4 & 41.2 & 257.6 & 15.2 \\
\hline
\end{tabular}

\section{$\underline{3.6 \text { Calibration Curves }}$}

Figure 6 shows the normalised results $B / B_{0}(\%)$ to compare singleplex and multiplex curves. All conjugates that were tested in Table 1 were used for singleplex analysis. FumB1-OVA was tested during singleplex analysis however the FumB1-KLH curve had better linearity and was chosen for multiplex testing. Therefore FumB1-KLH was chosen to proceed for multiplex analysis. The same T2 conjugate was chosen to move forward with multiplex analysis, however standards were adjusted in an attempt to further improve curve shape from $0 \mathrm{ng} / \mathrm{ml}$ to $10 \mathrm{ng} / \mathrm{ml}$. As the curve produced using the ZEN-KLH conjugate was still showing the worst signal to noise ratio compared to the other toxins, a different ZEN conjugate (ZEN-OVA) was evaluated with the experimental runs for multiplex analysis. A conjugate: polymer $(\mu \mathrm{g} / \mathrm{ml})$ of $75: 50(\mathrm{v} / \mathrm{v})$ was used.

\subsubsection{Singleplex curves}

The first toxin analysed was T2 (Figure 6 (a)). Variation defined here as the \%CV, which is indicated by the error bars on the graph, was low during each run. The first analysis carried out was the $0 \mathrm{ng} / \mathrm{ml}$ standard. On this run the $\Delta f$ was $963.01 \mathrm{kHz}$. This was a $78.5 \%$ increase from the hand-spotted chip subject to zero standard that was first tested on the PMD during conjugate: polymer ratio optimisation. Nevertheless, upon addition of standard the $\Delta f$ decreased expectedly apart from a slight unexpected increase in $\Delta \mathrm{f}$ upon injection of the last standard to $71.03 \mathrm{kHz}\left(7 \% \mathrm{~B} / \mathrm{B}_{0}\right)$. At $50 \mathrm{ng} / \mathrm{ml}$ the greatest inhibition occurred for any other T2 assay on the NPMD or PMD, when the $\Delta f$ decreased to $38.37 \mathrm{kHz}\left(4 \% \mathrm{~B} / \mathrm{B}_{0}\right)$.

During the FumB1 assay (Figure 6 (b)), as FumB1 toxin standard increased, the $\Delta f$ decreased as expected apart from the last injection at $100 \mathrm{ng} / \mathrm{ml}$ where the $\Delta \mathrm{f}$ increased slightly $(62.83 \mathrm{kHz})$ from the previous injection of $50 \mathrm{ng} / \mathrm{ml}(54.49 \mathrm{kHz})$. Furthermore, variation defined here as the \%CV, which is indicated by the error bars on the graph, was low during each run. 
During the ZEN-KLH assay (Figure 6 (c)) carried out on the PMD, the zero standard generated a $\Delta f$ of $191.95 \mathrm{kHz}$. Upon injection of the $5 \mathrm{ng} / \mathrm{ml}$ standard, the $\Delta \mathrm{f}$ decreased expectedly to $118 \mathrm{kHz}(61 \% \mathrm{~B} / \mathrm{B} 0)$. However, after this, the $\Delta \mathrm{f}$ did not decrease linearly as shown on the graph. The signal to noise ratio for the ZEN-KLH assay was low compared to the T2 and FumB1 assays.

(a) T2

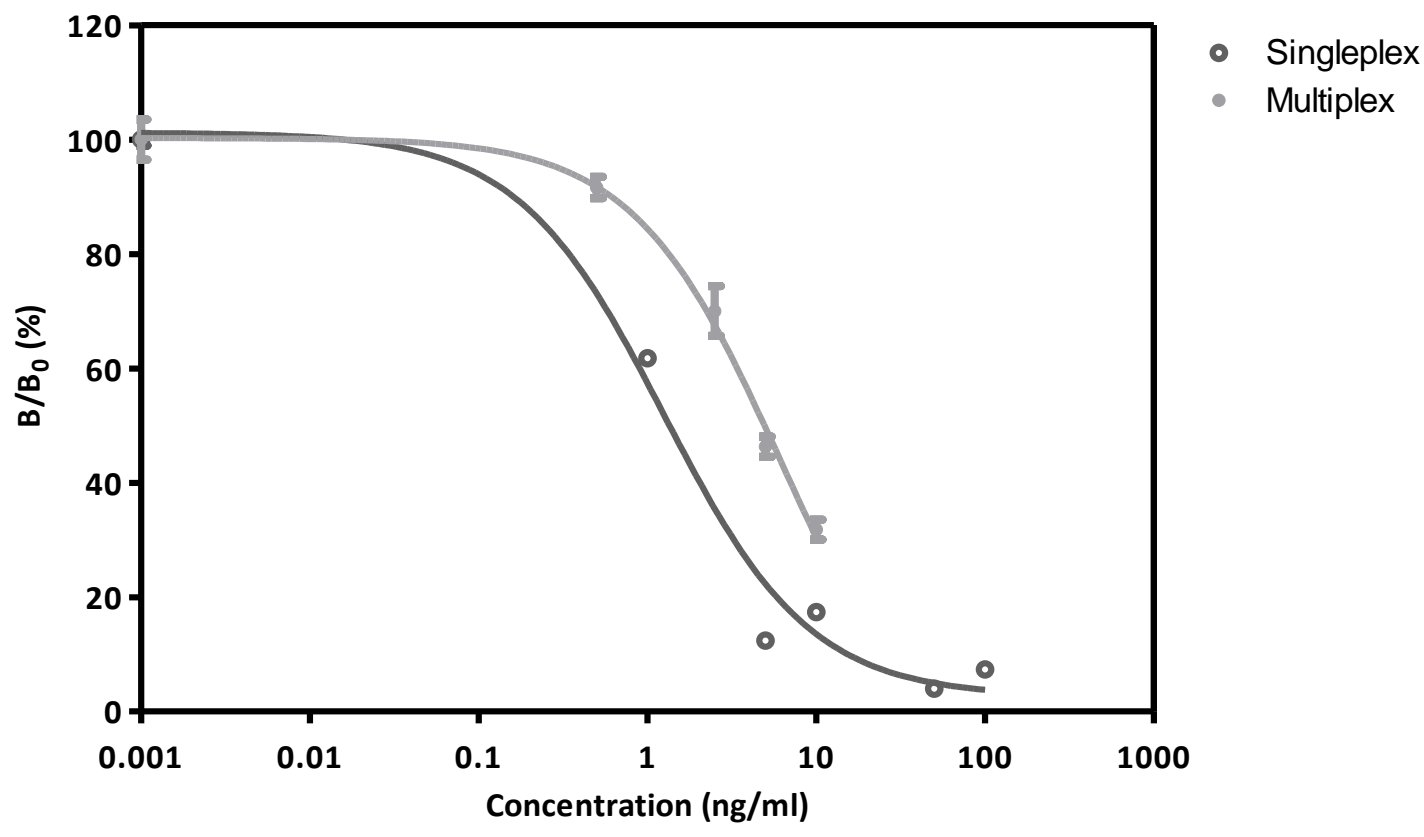

(b) FumB1

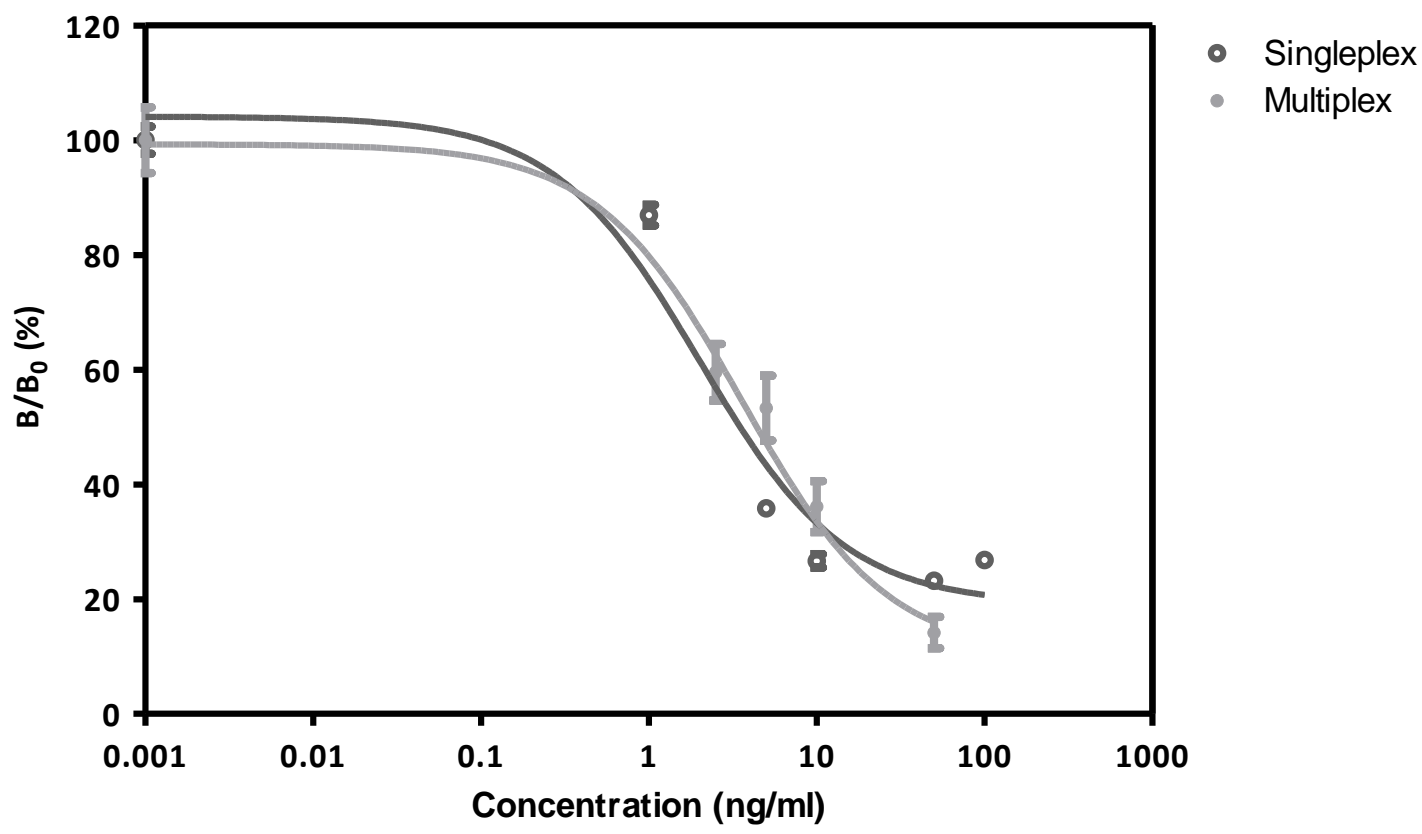


(c) ZEN

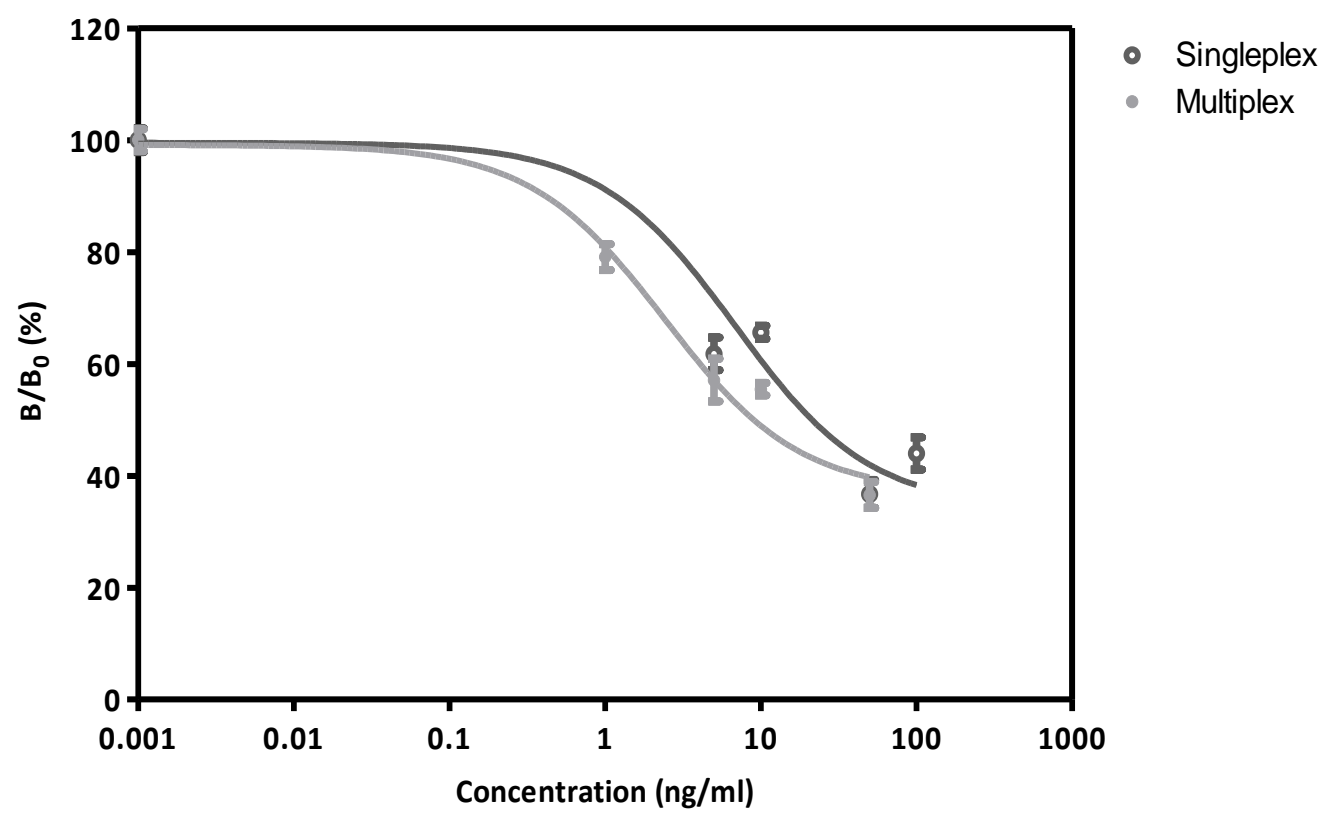

Figure 6. Singleplex and multiplex T2 (a), FumB1 (b) and ZEN (c) curves generated from assays conducted on the PMD. The conjugate: polymer ratio was $50 \mu \mathrm{g} / \mathrm{ml}: 100 \mu \mathrm{g} / \mathrm{ml}$ for the T2 assay and $50 \mu \mathrm{g} / \mathrm{ml}: 50 \mu \mathrm{g} / \mathrm{ml}$ for the FumB1 and ZEN assays. The Ab dilutions were $5 \mu \mathrm{g} / \mathrm{ml}$ of $T 2 \mathrm{mAB}$ and FUM $m A B$ and $10 \mu \mathrm{g} / \mathrm{ml}$ of ZEN $m A B$ during each assay

\subsubsection{Multiplex curves}

During the multiplex assay, linearity for all toxins improved in comparison to the singleplex assays. As the concentration of T2, FumB1, and ZEN toxin standards increased, the measured $\Delta f$ decreased as expected for each toxin. As a result, curve fitting improved during the multiplex assay for T2, FumB1, and ZEN in comparison to the respective singleplex assays.

For the T2 curve, even though a smaller range of concentration of standards was used during the multiplex calibration on comparing the data points of the singleplex and multiplex $\mathrm{T} 2$ curves, there is less inhibition of the $A b$ occurring during the multiplex assay as indicated by higher $\mathrm{B} / \mathrm{B}_{0} \%$ values. For example, during the singleplex assay, upon injection of $5 \mathrm{ng} / \mathrm{ml}$ and $10 \mathrm{ng} / \mathrm{ml}$ of $\mathrm{T} 2$ toxin standard, $B / \mathrm{B}_{0}$ values were $12.4 \%$ and $17.4 \%$, respectively. However, during the multiplex assay upon injection of the same $\mathrm{T} 2$ toxin standard concentrations, the $\mathrm{B} / \mathrm{B}_{0}$ values were $46.3 \%$ and $31.8 \%$, respectively. For the case of the T2 it would appear that there are some interferences present in the multiplex from the other reagents that is not occurring in the singleplex assay.

When the $\Delta f^{\prime}$ 's were normalized to their respective $B / B_{0}(\%)$ values, an almost identical overlap of the normalised calibration curves for FUM-KLH in the singleplex assay and the multiplex assay was apparent. During the multiplex assay, the signal to noise ratio improves for FumB1 as observed from the normalised differences $\left(B / B_{0}\right)$ for the highest toxin standard which was $14.2 \%$ during the multiplex assay and $26.8 \%$ during the singleplex assay.

For the ZEN curves, despite two different conjugates being used on the surface of the singleplex (ZEN$\mathrm{KLH}$ ) and multiplex (ZEN-OVA) assays, the calibration curves do not differ greatly. However, comparing the data points of the singleplex and multiplex ZEN curves, there is more inhibition of the Ab occurring during the multiplex assay as indicated by lower $B / B_{0} \%$ values. For example, during the singleplex assay, upon injection of $5 \mathrm{ng} / \mathrm{ml}, 10 \mathrm{ng} / \mathrm{ml}$ and $100 \mathrm{ng} / \mathrm{ml}$ of ZEN toxin standard, B/B $B_{0}$ values were $61.8 \%, 65.6 \%$ and $44.0 \%$, respectively. However, during the multiplex assay upon injection of the same ZEN toxin standard concentrations, the $\mathrm{B} / \mathrm{B}_{0}$ values were $57.1 \%, 55.5 \%$ and $36.6 \%$, respectively. 
Table 2. Sensitivity $\left(I C_{50}\right)$ and working ranges $\left(I C_{20}-I C_{80}\right)$ of T2, FumB1 and ZEN assays conducted on all MSMA biosensors, SPR and ELISA

\begin{tabular}{|c|c|c|c|c|c|c|c|c|c|}
\hline Mycotoxin & $\begin{array}{l}\text { Analytical } \\
\text { Method }\end{array}$ & $\begin{array}{l}\text { Instrumentation } \\
\text { used for } \\
\text { detection }\end{array}$ & $\begin{array}{l}\text { Mycotoxin } \\
\text { conjugate used }\end{array}$ & $\begin{array}{l}\text { Functionalisation } \\
\text { onto surface }\end{array}$ & $\begin{array}{l}\text { Curve type } \\
\text { (single or multiplex) }\end{array}$ & $\begin{array}{c}\mathrm{IC}_{50} \\
(\mathrm{ng} / \mathrm{mL}) \\
\end{array}$ & $\begin{array}{c}\mathrm{IC}_{20} \\
(\mathrm{ng} / \mathrm{mL})\end{array}$ & $\begin{array}{c}\mathrm{IC}_{80} \\
\text { (ng/mL) }\end{array}$ & $\begin{array}{l}\text { Lowest and highest } \\
\text { ML's in food (ppb) }\end{array}$ \\
\hline \multirow[t]{4}{*}{$\mathrm{T} 2$} & ELISA & Plate reader & T2-Transferrin & Adhesion & Singleplex & 235.6 & 58.9 & 942.4 & \multirow{4}{*}{$15-1000$} \\
\hline & SPR & Biacore & $\mathrm{T} 2$ & EDC/NHS & Singleplex & 2.6 & 0.7 & 10.4 & \\
\hline & MSMA & PMD & T2-Transferrin & Adhesion & Singleplex & 1.3 & 0.1 & 5.3 & \\
\hline & & & T2-Transferrin & Adhesion & Muliplex & 6.1 & 1.5 & 24.4 & \\
\hline \multirow[t]{5}{*}{ FumB1 } & ELISA & Plate reader & FumB1-KLH & Adhesion & Singleplex & 6.1 & 1.5 & 24.2 & \multirow{5}{*}{$200-4000$} \\
\hline & SPR & Biacore & FumB1 & $\mathrm{EDC} / \mathrm{NHS}$ & Singleplex & 15.1 & 3.8 & 60.2 & \\
\hline & MSMA & PMD & FumB1-KLH & Adhesion & Singleplex & 2.0 & 0.5 & 8.0 & \\
\hline & & & FumB1-OVA & Adhesion & Singleplex & 21.9 & 5.5 & 87.7 & \\
\hline & & & FumB1-KLH & Adhesion & Muliplex & 3.6 & 0.9 & 14.3 & \\
\hline \multirow[t]{4}{*}{ ZEN } & ELISA & Plate reader & ZEN-KLH & Adhesion & Singleplex & 8.5 & 2.1 & 34.2 & \multirow{4}{*}{$50-400$} \\
\hline & SPR & Biacore & ZEN & $\mathrm{EDC} / \mathrm{NHS}$ & Singleplex & 40.2 & 10 & 160.7 & \\
\hline & MSMA & PMD & ZEN-KLH & Adhesion & Singleplex & 6.8 & 2.7 & 44.1 & \\
\hline & & & ZEN-OVA & Adhesion & Muliplex & 2.4 & 0.6 & 9.6 & \\
\hline
\end{tabular}




\subsection{Sensitivity}

The calibration curves generated from each assay were used to obtain the $\mathrm{IC}_{50}$ values (concentration at which $50 \%$ inhibition of binding occurs) to assess sensitivity. Additionally, the $\mathrm{IC}_{80}$ and $\mathrm{IC}_{20}$ values (concentrations at which $80 \%$ and $20 \%$ inhibition of binding occurs, respectively) allowed determination of the working range of the assay $\left(\mathrm{IC}_{80}-\mathrm{IC}_{20}\right)$. (Table 2$)$.

Firstly, all IC 50 values obtained in assays conducted with the PMD are considerably below all maximum levels (ML's) for T2, ZEN and FumB1 in food and feed enforced in the European Union through Regulation (EC) No 1881/2006, 401/2006 and 519/2014 (Table 2). This excess in sensitivity potentially allows a substantial degree of sample dilution after extraction and sample preparation using previously developed and validated methodologies to minimize matrix effects.

The most sensitive result obtained from assays carried out on the MSMA devices was $1.3 \mathrm{ng} / \mathrm{ml}$, generated from the singleplex T2 assay using the PMD. In fact, this was the most sensitive result obtained throughout all technologies (including SPR and ELISA) for any toxin analysed during this project. The $\mathrm{IC}_{50}$ of the $\mathrm{T} 2$ assay carried out using SPR was $2.6 \mathrm{ng} / \mathrm{ml}$ which was more sensitive than the multiplex assay $(6.1 \mathrm{ng} / \mathrm{ml})$ carried out on the PMD. The $I C_{50}$ of the T2 ELISA was $235.6 \mathrm{ng} / \mathrm{ml}$, making it the least sensitive method for $\mathrm{T} 2$ detection in this study. In fact, this was the least sensitive result obtained across all analytical methods used for any toxin detection in this study.

In comparison to the other technologies (ELISA and SPR) used for FumB1 detection, the assays conduced on the MSMA device was most sensitive. Between singleplex and multiplex calibration curves developed using FumB1-KLH, sensitivity decreased from $2.0 \mathrm{ng} / \mathrm{ml}$ to $3.6 \mathrm{ng} / \mathrm{ml}$. The least sensitive result for FumB1 was $15.1 \mathrm{ng} / \mathrm{ml}$ which was obtained carrying out the FumB1 assay using SPR. The FumB1-KLH ELISA was more sensitive than SPR with an $\mathrm{IC}_{50}$ of $6.1 \mathrm{ng} / \mathrm{ml}$ but still less sensitive than any of the FumB1 assays carried out on the MSMA devices.

For the multiplex assay, ZEN-OVA was used instead of ZEN-KLH. Using the ZEN-OVA conjugate resulted in a smaller working range $\left(I C_{20}=0.6 \mathrm{ng} / \mathrm{ml}, I_{80}=9.6 \mathrm{ng} / \mathrm{ml}\right)$ than the ZEN-KLH singleplex assay but was more sensitive, with an $1 \mathrm{C}_{50}$ value of $2.4 \mathrm{ng} / \mathrm{ml}$. The ZEN assay carried out on SPR was the least sensitive $\left(I C_{50}=40.2 \mathrm{ng} / \mathrm{ml}\right)$, compared to the other assays carried out on SPR for the different toxins (FumB1 $\left.\mathrm{IC}_{50}=11.8 \mathrm{ng} / \mathrm{ml}\right),\left(\mathrm{T} 2 \mathrm{IC} \mathrm{C}_{50}=2.6 \mathrm{ng} / \mathrm{ml}\right)$.

\subsection{Assay interference}

As seen from Figure 7, for each assay, the greatest amount of inhibition occurred upon injection of $A b$ with toxin to which it is specific. The $B / B_{0}$ was $108 \%$ and $124 \%$ when FUM $A b$ mixed T2 and ZEN toxin standards were passed over the surfaces of FumB1 coated chips, respectively. The $B / B_{0}$ was $82 \%$ and $85 \%$ when ZEN Ab mixed with T2 and FumB1 toxin standards were passed over the surfaces of ZEN coated chips, respectively. B/B0 was $44 \%$, when T2 Ab mixed with $200 \mathrm{ng} / \mathrm{ml}$ of T2 standard was passed over the surface of a T2 coated chip. This was the least amount of inhibition that occurred upon addition of toxin specific standard, compared to the other $B / B_{0}$ results obtained when specific toxin was added. Nevertheless, the $B / B_{0}$ was still greater when unspecific standard was added to the $T 2 A b$ and passed over the surface of the T2 coated chip ( $81 \%$ when ZEN was added to the T2 Ab and $122 \%$ when FumB1 was added to the $T 2 \mathrm{Ab}$ ). 


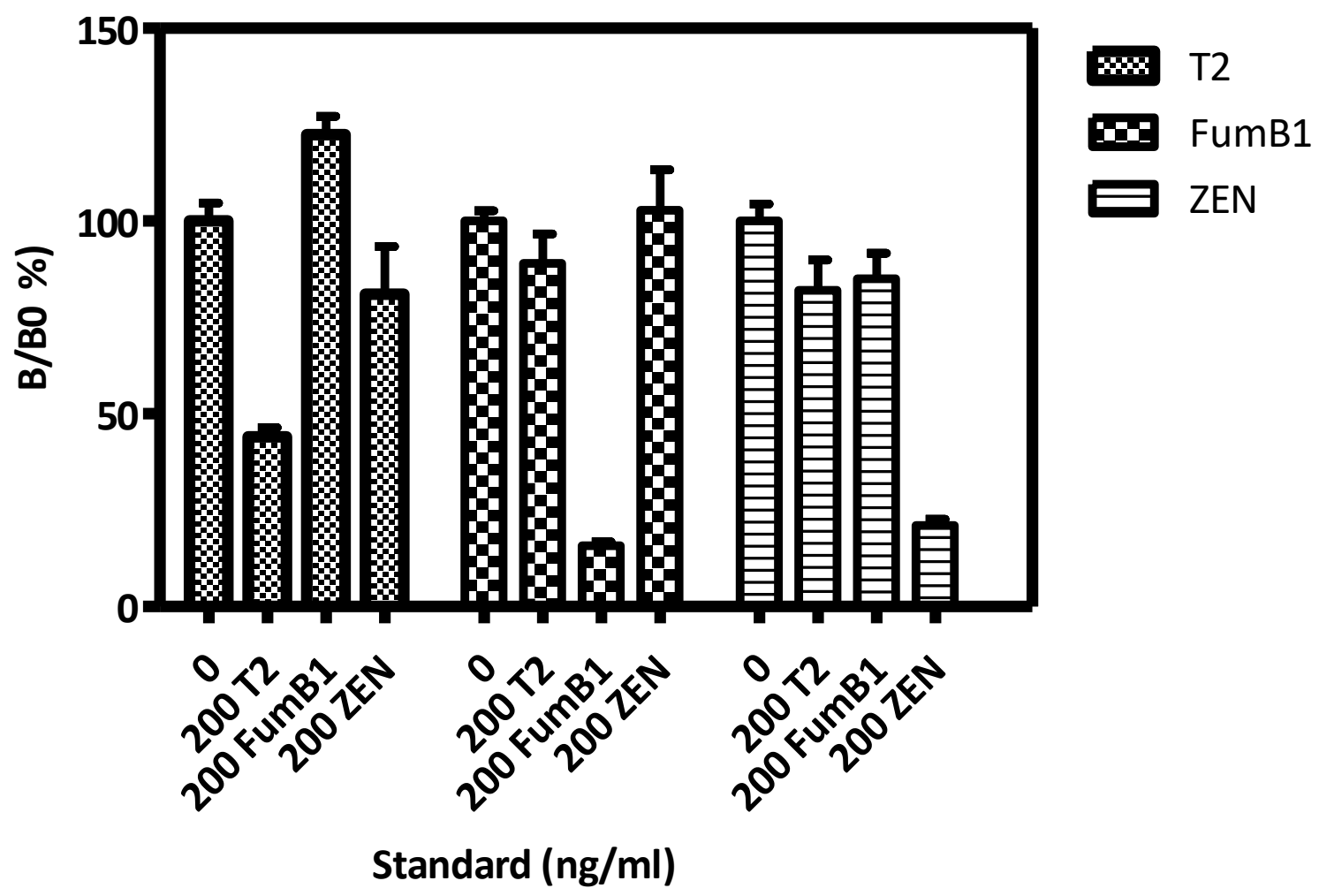

Figure 7. Interference between T2, FumB1 and ZEN assays.

\subsection{Intra and inter- spotting precision}

Intra and inter-assay precision are shown in Table 3. Average CV's obtained from intra spotting analysis for each toxin are all below $18 \%$. However, looking at individual days, \%CV's for FumB1OVA on day 1 and ZEN-KLH day 1 were over $20 \%$ at $21.12 \%$ and $23.63 \%$, respectively. Inter-assay CV's for T2, ZEN-KLH and FumB1-OVA were all below 20\%. The increase in inter-assay precision seen for FumB1-KLH is a result of the day 3 run which gave an increased $\Delta f$ of $420.67 \mathrm{kHz}$, compared to days 1 and 2 where the $\Delta f$ was 240.76 and 234.45, respectively. For T2-transferrin and ZEN-KLH, average CV's obtained from inter spotting analysis are both below $18 \%$. 
Table 3. Intra and Inter-spotting precision results for T2-Transferring, ZEN-KLH, FumB1-OVA and FumB1-KLH

\begin{tabular}{|c|c|c|c|c|c|c|}
\hline & & \multicolumn{4}{|c|}{ INTRA } & \multirow{2}{*}{$\begin{array}{l}\text { INTER } \\
\text { CV (\%) }\end{array}$} \\
\hline Toxin & Day & Average $(n=>30)$ & $S D$ & $C V(\%)$ & Average $(n=3)$ & \\
\hline \multirow[t]{3}{*}{ T2-transferrin } & 1 & 963.0 & 52.6 & 5.5 & 12.8 & 15.7 \\
\hline & 2 & 702.5 & 131.0 & 18.7 & & \\
\hline & 3 & 860.3 & 122.4 & 14.2 & & \\
\hline \multirow[t]{3}{*}{$Z E N-K L H$} & 1 & 192.0 & 23.0 & 12.0 & 17.3 & 17.6 \\
\hline & 2 & 203.3 & 33.0 & 16.2 & & \\
\hline & 3 & 208.4 & 49.2 & 23.6 & & \\
\hline \multirow[t]{3}{*}{ FUM-OVA } & 1 & 182.4 & 38.5 & 21.1 & 16.0 & 18.7 \\
\hline & 2 & 198.3 & 37.7 & 19.0 & & \\
\hline & 3 & 170.7 & 13.2 & 7.7 & & \\
\hline \multirow[t]{3}{*}{ FUM-KLH } & 1 & 234.5 & 38.6 & 16.5 & 13.3 & 31.6 \\
\hline & 2 & 240.8 & 24.4 & 10.1 & & \\
\hline & 3 & 420.7 & 55.5 & 13.2 & & \\
\hline
\end{tabular}

\section{Discussion}

\subsection{MSMA biosensor technology}

Table 4 shows a summary of the attributes of the MSMA biosensor technology in comparison to another biosensor (SPR) and test kit (ELISA) that are currently used for mycotoxin analysis in laboratory settings.

\subsection{Sensitivity}

In this study, the best sensitivities were obtained using the MSMA biosensor for each toxin in comparison to SPR and ELISA. Nevertheless, it is also important to compare results obtained from literature. Particularly where multiplexing abilities of biosensor technology have been employed. In a study by Joshi et al., [28] the group developed a 6-plex prototype nanostructured iSPR biosensor for the detection of 6 mycotoxins simultaneously. This biosensor technology is comparable to MSMA in the sense that both are also portable and label-free. The sensitivities obtained using the nanostructured iSPR biosensor as indicated by $\mathrm{IC}_{50}$ values during multiplex analysis in buffer was $10 \mathrm{ng} / \mathrm{ml}$ for T2, $8 \mathrm{ng} / \mathrm{ml}$ for FumB1 and $25 \mathrm{ng} / \mathrm{ml}$ for ZEN. The multiplex assays carried out using the MSMA biosensor in this project showed higher sensitivities, where the $\mathrm{IC}_{50}$ values were $6.09 \mathrm{ng} / \mathrm{ml}$ for $\mathrm{T} 2,3.6 \mathrm{ng} / \mathrm{ml}$ for FumB1 and $2.41 \mathrm{ng} / \mathrm{ml}$ for ZEN. Furthermore, these sensitivities obtained using the MSMA biosensor required a much lower concentrations of $A b$ than the nanoplasmonics iSPR biosensor. (Ab concentration was 50 times for FumB1, 125 times for ZEN and 250 times for T-2 using the nanostructured iSPR biosensor). One of the reasons for this was that the prototype iSPR sensitivity was less than that of the benchtop SPR instrument (Biacore).

However, other researchers have illustrated an extremely sensitive method using a fluorescent competitive immunoassay microarray based on a non-fouling polymer brush consisting of polyethylene glycol methacrylate-co-glycidyl methacrylate for the detection of aflatoxin, ochratoxin and zearalenone as template targets achieving wide dynamic ranges of 3 orders of magnitude and sensitivities of 4,4 and $3 \mathrm{pg} / \mathrm{mL}$ [29]. It was believed the sensitivity achieved was due to the uniformly large protein loading and high resistance to non-specific protein absorption. Schulz et al [30] also 
investigated the development of an electrochemical biochip as a portable and fully automated detection platform for low molecular weight toxins including mycotoxins. The dynamic range achieved was again three orders of magnitude with sensitivies of $\mathrm{ng} / \mathrm{mL}$ reported. Urusov et al. [31] also achieved the development of a multiple immunoenzyme assay for myotoxins with sensitivities in the low $\mathrm{ng} / \mathrm{mL}$ region for aflatoxin $\mathrm{B} 1$, Ochratoxin $\mathrm{A}$ and zearalenone.

Nevertheless, the better the sensitivity of an assay, the lower the useful working range will be. This was seen from all of the assays developed for T2, FumB1 and ZEN using the MSMA devices. Further investigation of the working range should be investigated for all three mycotoxins analysed in this study. By testing a range of lower Ab concentrations, it may be possible to find the optimal $A b$ concentration that yields a wide enough working range without compromising sensitivity of the assay above ML's. As the MSMA technology has been demonstrated as capable of detecting toxins with such high sensitivities, it seems that further investigation should also be carried out with toxins that have lower ML's. For example, during the singleplex $\mathrm{T} 2$ assay, the working range was $0.1 \mathrm{ng} / \mathrm{ml}\left(\mathrm{IC}_{20}\right)-5.3 \mathrm{ng} / \mathrm{mI}\left(\mathrm{IC}_{50}\right)$. This sensitivity would be more applicable to AFB1 and OTA analysis and where ML's are as low as $0.1 \mathrm{ppb}$ and $0.5 \mathrm{ppb}$, respectively.

\subsection{Calibration curves}

An issue with singleplex curves carried out on the MSMA devices was poor linearity. There is a combination of reasons as to why this may have occurred. Poor linearity can be a result of background noise due to unspecific binding to the detection surface. This could be possible during runs using the MSMA technology as antibodies do bind to gold surfaces. However, the PTHMMAA polymer was chosen specifically to be used with the MSMA technology as previous studies carried out with this polymer on gold surfaces show its credibility as a blocking agent. Vikholm-Lundin et al., [32] studied MDMA-BSA binding to gold surfaces with SPR. Sample analysis was conducted with PBS:saliva 3:1 solutions spiked with MDMA. It was found that non-specific binding of proteins and other interfering molecules from saliva was much lower on MDMA-BSA surfaces mixed with PTHMMAA polymer than MDMA-BSA alone. It is more likely that poor linearity was due to the restrictions of the one channel PMD to develop a calibration curve. Because surface coating was only by adhesion, the pixels on the surface of one MSMA chip cannot be regenerated whereby the toxin-conjugate can remain on the surface of the chip and subsequent injections of Ab-standard can occur thereafter. Consequently, only one Ab-standard mixture can be analysed per chip on the one channel PMD. Therefore, it is very likely that surface coating differed slightly from chip to chip. Currently the nano-spotting system is only capable of spotting one chip at a time, meaning that despite chips being spotted on the same day, the chip spotted first would be exposed to freshly prepared coating solution and the chip spotted last was exposed to conjugate and polymer that had been in the microtitre plate for a slightly longer time. This would explain the slight unexpected increase in $\Delta f$ upon injection of the last standard to $71.03 \mathrm{kHz}(7 \% \mathrm{~B} / \mathrm{B} 0)$ during the singleplex $\mathrm{T} 2$ assay using the PMD.

Another issue which mainly effected the ZEN-KLH assays, was low signal to noise ratio. Poor Ab specificity to the toxin can be the reason for this. However, Ab specificity can be ruled out as the issue in this case as when using the same ZEN-KLH conjugate during the ELISA at $100 \mathrm{ng} / \mathrm{ml}$ the $\mathrm{B} / \mathrm{B}_{0}$ was $18.5 \%$, which is better than the $100 \mathrm{ng} / \mathrm{ml}$ injection of ZEN toxin standard during the ZEN-KLH assay carried out on the PMD (44\% B/B0). It is therefore possible that despite attempts to do so, the antibody concentration used for ZEN-KLH assays $(10 \mathrm{ug} / \mathrm{ml})$ was not optimal with the conjugate: polymer ratio on the surface $(50: 50 \mu \mathrm{g} / \mathrm{ml})$. Therefore, a checkerboard analysis with a range of coating concentrations and a range of Ab concentrations needs to be investigated for the ZEN-KLH assay. This could be tested easily using the nano-spotter and the four channel NPMD where a range of conjugate: polymer ratios could be spotted onto individual pixels and four different $A b$ concentrations could be analysed on a single chip. 
Table 4 Attributes of ELISA and MSMA and SPR biosensor technology. *Speed of analysis does not include sample preparation.

\begin{tabular}{|c|c|c|c|c|}
\hline PARAMETER & $\begin{array}{l}\text { PORTABLE MSMA } \\
\text { TECHNOLOGY }\end{array}$ & $\begin{array}{c}\text { NON-PORTABLE MSMA } \\
\text { TECHNOLOGY }\end{array}$ & SPR & ELISA \\
\hline $\begin{array}{l}\text { DETECTION } \\
\text { CAPABILITY }\end{array}$ & $\begin{array}{l}\text { T2 Toxin, FumB1 and ZEN } \\
\text { detected simultaneously }\end{array}$ & $\begin{array}{l}\text { T2 Toxin, FumB1 and ZEN } \\
\text { detected on three separate } \\
\text { assays }\end{array}$ & $\begin{array}{l}\text { T2 Toxin, FumB1 and ZEN } \\
\text { detected on three separate } \\
\text { assays }\end{array}$ & $\begin{array}{l}\text { T2 Toxin, FumB1 and ZEN } \\
\text { detected on three separate } \\
\text { assays }\end{array}$ \\
\hline EASE OF USE & $\begin{array}{l}\text { Very simple to use, requires } \\
\text { minimal training }\end{array}$ & $\begin{array}{l}\text { Simple to use but requires } \\
\text { initial training }\end{array}$ & $\begin{array}{l}\text { Simple to use but requires } \\
\text { initial training }\end{array}$ & $\begin{array}{l}\text { Simple to use but requires } \\
\text { initial training }\end{array}$ \\
\hline $\begin{array}{l}\text { SPEED OF } \\
\text { ANALYSIS* }\end{array}$ & $\begin{array}{l}\text { Approximately } 10 \text { minutes } \\
\text { (results generated in under } 5 \\
\text { minutes) }\end{array}$ & $\begin{array}{l}\text { Approximately } 50 \text { minutes } \\
\text { (with } 4 \text { samples) }\end{array}$ & $\begin{array}{l}\text { Approximately } 50 \text { minutes } \\
\text { (with } 4 \text { samples) }\end{array}$ & Approximately 4 hours \\
\hline PORTABILITY & Yes & No & No & No \\
\hline REGENERATION & $\begin{array}{l}\text { Chips can be regenerated } \\
\text { and reused clearing the } \\
\text { surface of previous coating } \\
\text { analyte }\end{array}$ & $\begin{array}{c}\text { Chips can be regenerated } x 3 \\
\text { and reused clearing the } \\
\text { surface of previous coating } \\
\text { analyte }\end{array}$ & $\begin{array}{l}\text { Chips can be regenerated } \\
\text { without effecting the coating } \\
\text { analyte for multiple runs }\end{array}$ & Not possible \\
\hline BENEFITS & $\begin{array}{l}\text { Relatively cheap, sensitive, } \\
\text { results in real-time, label- } \\
\text { free, no washing steps, no } \\
\text { long incubations, multiplex } \\
\text { analysis, small reagent and } \\
\text { sample volumes }\end{array}$ & $\begin{array}{l}\text { Automated, results in real } \\
\text { time, sensitive, label-free, no } \\
\text { washing steps, no long } \\
\text { incubation periods, multiplex } \\
\text { analysis, small reagent and } \\
\text { sample volumes }\end{array}$ & $\begin{array}{l}\text { Automated, results in real } \\
\text { time, sensitive but may } \\
\text { require labels or high } \mathrm{Ab} \\
\text { concentrations to achieve, } \\
\text { no washing steps, no } \\
\text { incubation periods }\end{array}$ & $\begin{array}{l}\text { Relatively cheap, high } \\
\text { throughput, sensitive and } \\
\text { selective }\end{array}$ \\
\hline LIMITATIONS & $\begin{array}{l}\text { One sample analysed at a } \\
\text { time }\end{array}$ & $\begin{array}{l}\text { Automated biosensor is } \\
\text { costly }\end{array}$ & $\begin{array}{l}\text { Biosensor is costly. Can } \\
\text { require labels to enhance } \\
\text { sensitivity }\end{array}$ & $\begin{array}{c}\text { Time consuming, laborious, } \\
\text { interpretation and analysis } \\
\text { of results are required }\end{array}$ \\
\hline
\end{tabular}




\section{Conclusion}

To conclude, this study has shown the highly promising usage of an MSMA biosensor for the determination of small molecular weight toxins using mycotoxin analysis as a model example. The key features that MSMA technology offers which this study has demonstrated is portable multi-toxin detection with high sensitivity for a single sample. Furthermore, the ability to functionalise individual pixels on a single chip using nano-spotting technology has been demonstrated in this work. As there are 64 pixels, 32 analytes could theoretically be detected from one sample (where $n=2$ ) or 16 (where $n=4$ ). The fact that multiplexing has also been demonstrated on a portable device that is easy to use and requires minimal training, highlights the promising integration of MSMA bio-sensing technology for on-site analysis. In terms of assay instrumental running time, the PMD is very rapid analysing up to 3 toxins from one sample in approximately 10 minutes (results generated in under 5 minutes). However, this is relative to the results from this study and many more analytes could be printed on the devices and detected from a single sample with further development. The running time of the NPMD with 4 samples under analysis is approximately 50 minutes. Whilst this is longer the device is automated, so the analyst does not have to be present. Furthermore, the instrumental set-up time is short with the easy to navigate software, taking between 5-10 minutes. This study in principle illustrates the capabilities of this technology for the multiplex analysis of small molecular weight toxins such as mycotoxins. However, the future steps would be the analysis of real samples for the technology to be considered for full application in this field.

\section{Compliance with ethical standards}

Research involving animal experiments were performed in accordance with the UK Animals Scientific Procedures Act 1986 under the license PPL2756 issued on the 12/02/2014 by the Department of Health, Social Services and Public Safety for Northern Ireland.

\section{Acknowledgements}

$\mathrm{PN}$ was the main author executing the experiments, conducting data analysis and writing. $\mathrm{MO}$ and $\mathrm{KC}$ produced antibodies used in the study. KC and PN made protein conjugates used in this study. KC, SA and AS contributed to the concept of this study, supervised this work and provided guidance and assistance during experimental planning. KC, SA, AS and MO provided advice and assisted in drafting the final document. The authors would like to acknowledge Prof Chris Elliott at Queen's University Belfast for his support in part for the supervision of this work. 


\section{References}

[1] S. Marin, A.J. Ramos, G. Cano-Sancho and V. Sanchis, Mycotoxins: Occurrence, toxicology, and exposure assessment, Food Chem. Toxicol., 60 (2013) 218-237, https://doi.org/10.1016/j.fct.2013.07.047

[2] M.J. Sweeney and D.W. Dobson, Mycotoxin production by Aspergillus, Fusarium and Penicillium species, Int. J. Food Microbiol., 43 (1998) 141-158, https://doi.org/10.1016/S0168-1605(98)00112-3

[3] A. Raiola, G.C. Tenore, L. Manyes, G. Meca and A. Ritieni, Risk analysis of the main mycotoxins occurring in food for children: An overview. Food Chem. Toxicol., 84 (2015) 169-180, https://doi.org/10.1016/j.fct.2015.08.023

[4] European Commission: Commission Regulation (EC) No 1881/2006 of 19 December 2006 setting maximum levels for certain contaminants in foodstuffs, Official J Eur Union 2006 L364: 5-24, https://www.legislation.gov.uk/eur/2006/1881

[5] European Commission: Commission Regulation (EC) Commission Regulation (EC) No 401/2006 of 23 February 2006 laying down the methods of sampling and analysis for the official control of the levels of mycotoxins in foodstuffs, Official J Eur Union, 2006 L70:12, https://www.legislation.gov.uk/eur/2006/401

[6] European Commission: Commission Regulation (EU) No 519/2014 of 16 May 2014 amending Regulation (EC) No 401/2006 as regards methods of sampling of large lots, spices and food supplements, performance criteria for T-2, HT-2 toxin and citrinin and screening methods of analysis, Official J Eur Union, 2014 L147:29-43, https://www.legislation.gov.uk/eur/2014/519

[7] European Commission: Commission Recommendation of 27 March 2013 on the presence of T-2 and HT-2 toxin in cereals and cereal products (2013/165/EU). Off. J. Eur. Union, 2013, L91:12-15, https://eur-lex.europa.eu/legalcontent/EN/TXT/PDF/?uri=CELEX:32013H0165

[8] B. De Santis, F. Debegnach, E. Gregori, S. Russo, F. Marchegiani, G. Moracci and C. Brera, Development of a LC-MS/MS Method for the Multi-Mycotoxin Determination in Composite Cereal Based Samples, Toxins, 9 (2017) 169, https://doi.org/10.3390/toxins9050169

[9] M.U. Ahmed, M. Zourob and E. Tamiya. E, Food Biosensors. The Royal Society of Chemistry: UK, Cambridge (2017), https://b-ok.cc/book/2849816/42e945

[10] A. Alshannaq and J.H. Yu, Occurrence, Toxicity, and Analysis of Major Mycotoxins in Food, Int. J. Environ. Res. Public Health, 14 (2017) 632, https://doi.org/10.3390/ijerph14060632

[11] F. Berthiller, C. Brera, M.H. Iha, R. Krska, V.M.T. Lattanzio, S. MacDonald, R.J. Malone, C. Maragos, M. Solfrizzo, M. Stranska-Zachariasova, J. Stroka and S.A. Tittlemier, Developments in mycotoxin analysis: an update for 2015-2016. World Mycotoxin Journal, 10 (2017) 5-29, https://doi.org/10.3920/WMJ2016.2138 
[12] W. Li, S. Powers and S.Y. Dai, Using commercial immunoassay kits for mycotoxins: 'joys and sorrows'? Rapid methods for mycotoxin detection. World Mycotoxin Journal, 7 (2014) 417 - 430, https://doi.org/10.3920/WMJ2014.1715

[13] G. Chen, X. Zhao, X. Wang, H. Jin, S. Li, S. Dong, A.J. Flewitt, W.I. Milne and J.K. Luo, Film bulk acoustic resonators integrated on arbitrary substrates using a polymer support layer. Scientific Reports, 5 (2015) 9510, https://doi.org/10.1038/srep09510

[14] G. Rughoobur, H. Sugime, M. DeMiguel-Ramos, T. Mirea, S. Zheng, J. Robertson, E. Iborra and A.J. Flewitt, Carbon nanotube isolation layer enhancing in-liquid quality-factors of thin film bulk acoustic wave resonators for gravimetric sensing. Sens. Actuators B Chem., 261 (2018) 398407, https://doi.org/10.1016/j.snb.2018.01.067

[15] G. Carlotti, Elastic Characterization of Transparent and Opaque Films, Multilayers and Acoustic Resonators by Surface Brillouin Scattering: A Review. Appl. Sci., 8 (2018) 124, https://doi.org/10.3390/app8010124

[16] Y. Zhang, J. Luo, A.J. Flewitt, Z. Cai and X. Zhao, Film bulk acoustic resonators (FBARs) as biosensors: A review. Biosens. Bioelectron., 116 (2018) 1-15, https://doi.org/10.1016/j.bios.2018.05.028

[17] M. Nirschl, A. Rantala, K. Tukkiniemi, S. Auer, A.C. Hellgren, D. Pitzer, M. Schreiter and I. Vikholm-Lundin, CMOS-integrated film bulk acoustic resonators for label-free biosensing. Sensors, 10 (2010) 4180-4193, https://doi.org/10.3390/s100504180

[18] A. Molinelli, K. Grossalber, M. Führer, S. Baumgartner, M. Sulyok and R. Krska, Development of qualitative and semiquantitative immunoassay-based rapid strip tests for the detection of T-2 toxin in wheat and oat, J. Agric. Food Chem, 56 (2008) 2589-2594, https://doi.org/10.1021/jf0404804

[19] Y. Sheng, W. Jiang, S. De Saeger, J. Shen, S. Zhang and Z. Wang, Development of a sensitive enzyme-linked immunosorbent assay for the detection of fumonisin B1 in maize. Toxicon, 60 (2012) 1245-1250, https://doi.org/10.1016/j.toxicon.2012.08.011

[20] S.H. Cha, S.H. Kim, K. Bischoff, H.J. Kim, S.W. Son and H.G. Kang, Production of a highly group-specific monoclonal antibody against zearalenone and its application in an enzymelinked immunosorbent assay. J Vet Sci. 13 (2012) 119-125;

https://doi.org/10.4142/jvs.2012.13.2.119

[21] F.S. Chu and I. Ueno, Production of an antibody against aflatoxin B1. Appl. Environ. Microbiol., (1977) 1125-1128, https://doi.org/10.1128/AEM.33.5.1125-1128.1977

[22] H.O. Arola, A. Tullila, H. Kiljunen, K. Campbell, H. Siitari, TK Nevanen, Specific noncompetitive immunoassay for HT-2 mycotoxin detection. Anal. Chem., 88 (2016) 24462452, https://doi.org/10.1021/acs.analchem.5b04591

[23] M. Oplatowska-Stachowiak, N. Sajic, Y. Xu, S.A. Haughey, M.H. Mooney, Y.Y. Gong, R. Verheijen and C.T. Elliott, Fast and sensitive aflatoxin B1 and total aflatoxins ELISAs for analysis of peanuts, maize and feed ingredients. Food Control, 63 (2016) 239-45, https://doi.org/10.1016/j.foodcont.2015.11.041 
[24] G. Kohler and C. Milstein, Continuous cultures of fused cells secreting antibody of predefined specificity, Nature, 256 (1975) 495-497; https://doi.org/10.1038/256495a0

[25] M. Nirschl, A. Blüher, C. Erler, B. Katzschner, I. Vikholm-Lundin, S. Auer, J. Vörös, W. Pompe, M. Schreiter and M. Mertig, Film bulk acoustic resonators for DNA and protein detection and investigation of in vitro bacterial S-layer formation. Sens. Actuators A Phys., 156(1) (2009) 180-184, https://doi.org/10.3390/s100504180

[26] S. Auer, M. Nirschl, M. Schreiter and I. Vikholm-Lundin, I, Detection of DNA hybridisation in a diluted serum matrix by surface plasmon resonance and film bulk acoustic resonators. Anal Bioanal Chem, 400 (2011) 1387-1396, https://doi.org/10.1007/s00216-011-4871-0

[27] W.M. Albers, S. Auer, H. Helle, T. Munter and I. Vikholm-Lundin, Functional characterisation of Fab'-fragments self-assembled onto hydrophilic gold surfaces. Colloids Surf B, 68 (2009) 193-199, https://doi.org/10.1016/j.colsurfb.2008.10.001

[28] S. Joshi, A. Segarra-Fas, J. Peters, H.A. Zuilhof, T. van Beek and M.W.F. Nielen, Multiplex surface plasmon resonance biosensing and its transferability towards imaging nanoplasmonics for detection of mycotoxins in barley. Analyst, 141 (2016) 1307-1318, https://doi.org/10.1039/C5AN02512E

[29] W. Hu, X. Li, G. He, Z. Zhang, X. Zheng, P. Li and C.M. Li, Sensitive competitive immunoassay of multiple mycotoxins with non-fouling antigen microarray Biosens. Bioelectron., 50 (2013) 338-344342; https://doi.org/10.1016/j.jcis.2014.06.007

[30] K. Schulz, C. Pohlmann, R. Dietrich, E. Martlbauer and T. Elbner, Electrochemical biochip assays based on anti-idiotypic antibodies for rapid and automated on-site detection of low molecular weight toxins. Frontiers in Chemistry, 7 (2019) 31, https://doi.org/10.3389/fchem.2019.00031

[31] A.E. Urusov, A.V. Zherdev, A.V. Petrakova, E.G. Sadykhov, O.V. Koroleva and B.B. Dzantiev, Rapid multiple immunoenzyme assay of mycotoxins, Toxins 7 (2015) 238-254, https://doi.org/10.3390/toxins7062134

[32] I. Vikholm-Lundin, S. Auer and A.C. Hellgren, Detection of 3,4methylenedioxymethamphetamine (MDMA, ecstasy) by displacement of antibodies. Sens. Actuators B Chem., 156 (2011) 28-34, https://doi.org/10.1016/j.snb.2011.03.069 


\section{Supplementary Material}

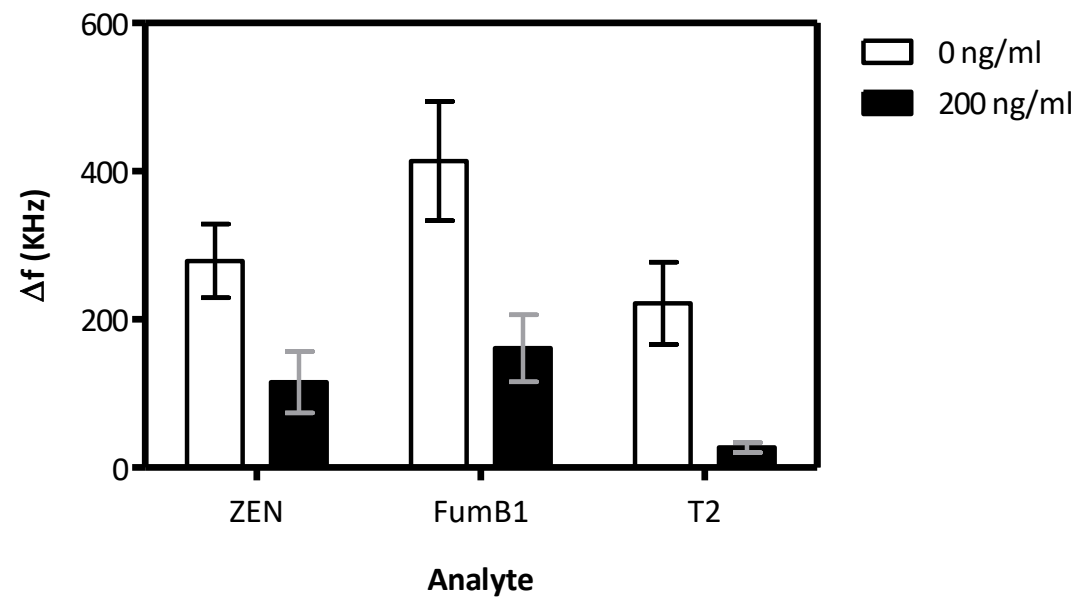

Fig. S1. Optimal measurable frequency changes ( $\triangle f)$ of pixels coated with ZEN-KLH, FumB1$K L H$, and T2-Transferrin conjugates upon respective antibody and standard injections
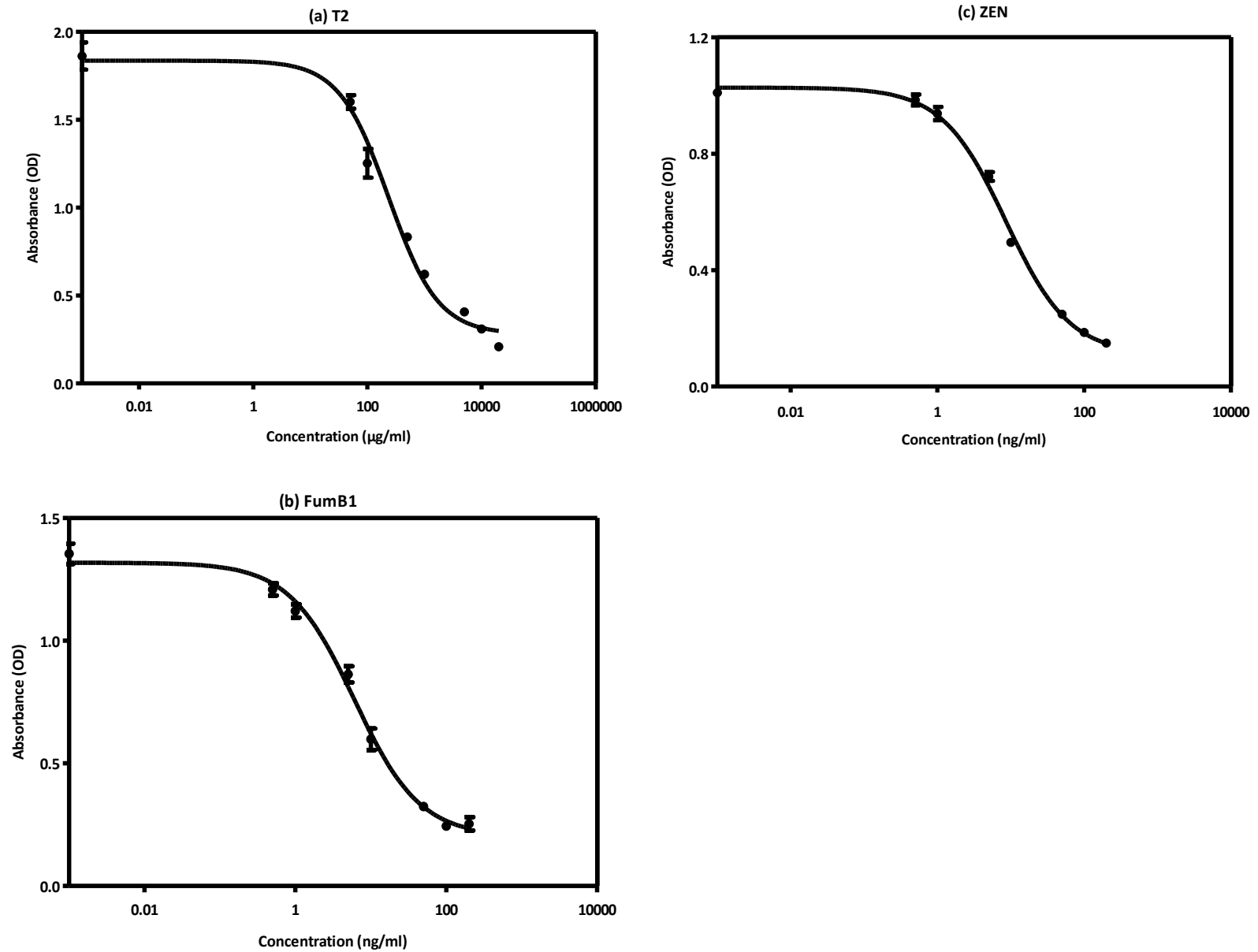

Fig S2. Calibration curves for (a) T2, (b) FumB1 and (c) ZEN generated from ELISA assays 
(a) T2

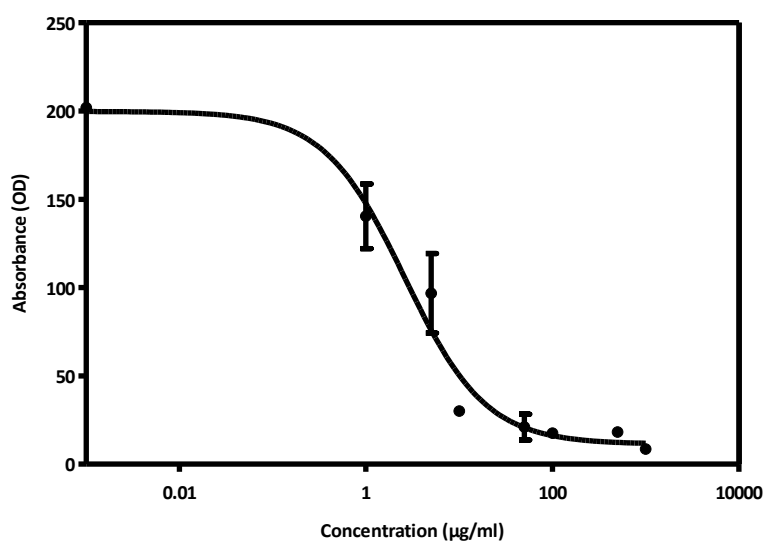

(b) FumB1

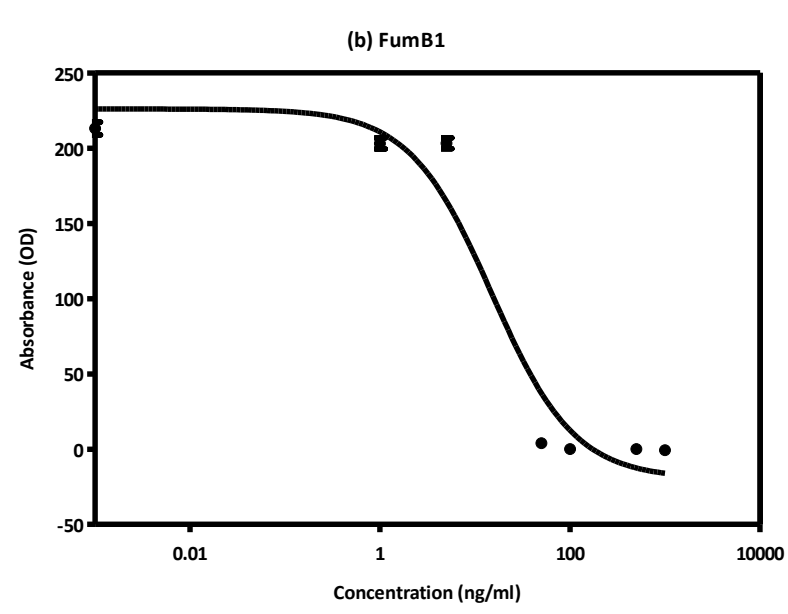

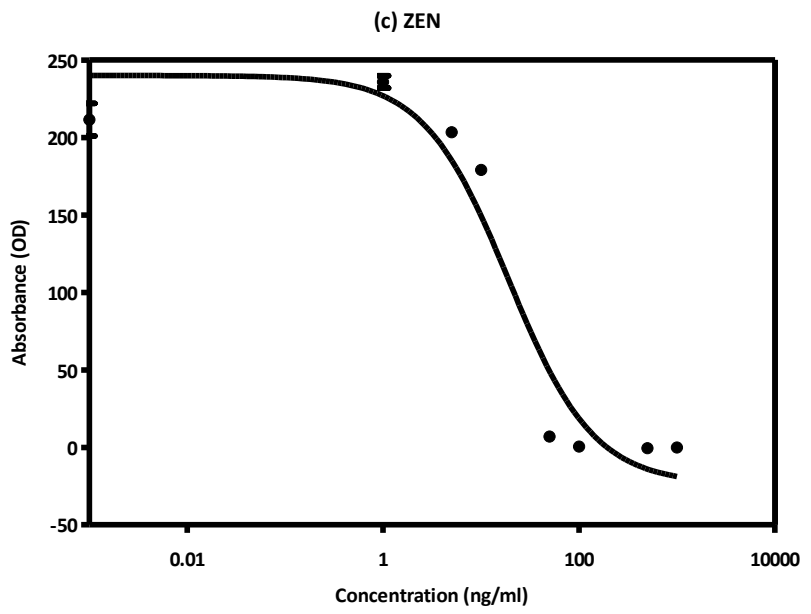

Fig S3. Calibration curves for (a) T2, (b) FumB1 and (c) ZEN generated from SPR assays conducted on Biacore $Q$ 